\title{
Aspectos diacrónicos de la ordenación del territorio de la cuenca del río Alberche
}

\author{
María Sotelo PÉREZ \\ Grupo de Investigación de la UCM: "Desarrollo y Gestión Ambiental del Territorio" \\ maria_sotelo_perez@hotmail.com
}

Recibido: 5 de junio de 2012

Enviado a evaluar: 7 de junio de 2012

Aceptado: 27 de julio de 2012

\begin{abstract}
RESUMEN
El ámbito de planificación del presente estudio es un sector del borde de la corona metropolitana suroeste de Madrid, integrado por los términos municipales de El Álamo, Navalcarnero, Villamanta y Sevilla la Nueva, que se encuadra en la comarca de la cuenca del Río Alberche. Las características del medio natural, la peculiar morfología de los asentamientos de población, junto con la singular organización y dinámica económica, la inmigración creciente en los últimos tiempos y la estacionalidad de la residencia, ha dado lugar a un modelo de relaciones y flujos que interrelacionan a los municipios entre sí, y que se manifiesta en desplazamientos poblacionales diarios, por motivos laborales y no laborales, e importantes fenómenos de terciarización, lo que confiere su mayor singularidad y principal característica, junto con la función de núcleos vertebradores de la comarca de la cuenca del río Alberche. A través del estudio de caso, con la metodología indagatoria, nos aproximaremos al estudio e investigación de la problemática relacionada con municipios que quedan inscritos en espacios dentro de figuras de protección (Parque Regional del curso medio del río Guadarrama) y otros, que no. Con todo ello, tras el análisis previo, analizaremos la problemática.
\end{abstract}

Palabras clave: Cambios, Transformación espacial, Espacios protegidos.

\section{Diachronic aspects of land planning of the Alberche river basin}

\begin{abstract}
The planning scope of this study is a section of the edge of the metropolitan area southwest of Madrid, comprising the townships of Alamo, Navalcarnero, Villamanta and Sevilla la Nueva, which falls in the region of the Rio Alberche. The characteristics of the natural environment, the peculiar morphology of population settlements, together with the unique organization and economic dynamics, increased immigration in recent times and the seasonal residence, has resulted in a pattern of relationships and flows that interrelate to municipalities each other and manifested in population movements daily for work and labor, and important phenomena of outsourcing, which gives the most singular and main feature, along with the role of backbone of the region of Alberche river basin. Through the case study, questioning the methodology, we approach the
\end{abstract}


study and research issues related to municipalities that are enrolled in spaces within the forms of protection (Regional Park of the middle river Guadarrama) and others not. All in all, after the previous analysis, we analyze the problem.

Keywords: Change, Spatial Transformation, Protected Areas.

\section{Aspects diachroniques de l'aménagement du territoire du bassin de la rivière Alberche}

\section{RÉSUMÉ}

Le champ de planification de cette étude est constitué par un secteur en bordure de la couronne métropolitaine sud-ouest de Madrid, composé des municipalités de El Álamo, Navalcarnero, Villamanta et Sevilla la Nueva, qui se situent dans le bassin de la rivière Alberche. Les caractéristiques de l'environnement, la morphologie particulière de l'habitat humain auxquelles on ajoute l'organisation singulière et la dynamique économique, la croissance récente de l'immigration et le caractère saisonnier de la résidence, ont donné lieu à un modèle de relations et des flux qui mène les municipalités à se relationner entre eux et qui se manifeste par des déplacements journaliers de la population, pour le motif travail ou non et aussi aux importants phénomènes de tertiarisation, ce qui lui confère sa majeure singularité et sa principale caractéristique à laquelle on ajoute la fonction de noyaux de cohésion qui représente pour la région du bassin de la rivière Alberche. À travers cette étude, par le biais d'une métodologie d'enquête, nous nous approchons de l'étude et de la recherce de la problématique liée aux municipalités qui font partie de l'espace ayant des éléments de protection (le Parc Régional du cours moyen de la rivière Guadarrama) et aux autres qui n'en font pas partie. Avec tout cela, après l'analyse prèalable, nous allons proceder à analyse de la problématique.

Mot clé: Changements, Transformation spatiale, Zones protégées.

\section{INTRODUCCIÓN}

La zona de estudio se sitúa en la segunda corona metropolitana de Madrid, y hasta el momento actual, debido a las menores posibilidades de comunicación, se ha visto perjudicada respecto a los núcleos de la primera corona metropolitana como Alcorcón, Móstoles, Fuenlabrada, etc., que han tenido crecimientos exponenciales, frente a crecimientos menores de la comarca estudiada. En este sentido la mayor distancia existente a otros municipios ha provocado su menor crecimiento, al contrario que otros municipios que lo han hecho por la cercanía a Madrid y a su vez por una buena dotación infraestructural, además de que ofrecían abundancia de suelo mucho más cercano a la capital. El proceso expansivo constante de Madrid y la actual coyuntura ha favorecido el acercamiento y expansión de la zona de estudio con proyectos a desarrollar interesantes como el metro ligero, la ampliación de la A-5, etc. A pesar de todo, la densa red de comunicaciones (M-507, M-404, R-5, A-5 ...) ha favorecido el desarrollo de la zona de estudio ya que facilita el acceso a la comarca 
estudiada (amén de los movimientos existentes entre los municipios que lo configuran), tanto desde el centro de la capital como desde municipios de su entorno que, de vistas al futuro deben ser bidireccionales. Las transformaciones recientes de este territorio se producen en el marco de cuatro consideraciones principales: los efectos socioeconómicos, los efectos espaciales, la propia estructura funcional de los espacios y los efectos ambientales. Estas consideraciones se interrelacionan dando lugar a lo que podríamos denominar nuevo espacio residencial, en el que junto a la segunda residencia ha tomado forma todo un entramado urbano de residencia permanente. La actividad económico de a zona ha traído consigo un considerable aumento de los efectivos demográficos como consecuencia de la inmigración y de los movimientos pendulares entre la Comarca estudiada y la Corona metropolitana. La concentración de la población se produce esencialmente por su relación con los servicios, la construcción y la industria. El sector agrario perdió su carácter estructurante de la economía comarcal y acusa los efectos de abandono de la actividad (a excepción de los viñedos de propiedad privada, vinculados a la denominación de origen de "vinos de Madrid"), aunque aún se fomenta el aprovechamiento de su potencial productivo, especialmente, cultivos agrícolas (secano mixto), pastoreo y aprovechamientos forestales. El sector industrial se centra, no sólo en el sector de la construcción, sino que se han desarrollado industrias como las del automóvil, vitivinícola y cervecera, metálica, manufacturera, química y energética, principalmente. El sistema de relaciones tiene como única dirección Madrid y los núcleos del área metropolitana, y son en su mayor parte unidireccionales, sobre todo por la inexistencia de determinados servicios que no pueden prestarse en la comarca. En lo referente a la estructuración del territorio y al sistema tradicional de núcleos de población nos encontramos ante cuatro núcleos base de población (población concentrada); correspondientes a los centros urbanos de cada uno de los municipios que configuran nuestra zona de estudio y, de forma aislada, algunos asentamientos dispersos en el territorio, correspondientes a urbanizaciones. Así mismo, cabe destacar la importancia que para la zona tiene formar parte del Parque Regional del curso medio del Guadarrama, puesto que, en principio, debería otorgarle un input, un valor añadido, en su configuración espacial y su desarrollo sostenible, económica, social y medioambiental.

Con todo ello, tras la descripción y el análisis de cada uno de los sistemas que configuran nuestro territorio, y a través de la premisa de considerar nuestro ámbito de planificación como un centro de expansión demográfica, con lo que ello conlleva el crecimiento económico y la demanda de suelo para construcción de vivienda, los principales objetivos a alcanzar son los siguientes;

- La mejora en la conectividad entre el ámbito de planificación y la corona metropolitana, favoreciendo tanto el transporte privado vía carreteras, como el transporte público vía carreteras y ferroviario.

- Hacer frente, de una manera sostenible, a las demandas de la población (una población que se incrementa progresivamente).

- Preservar y conservar el medio natural, sobre todo la zona del Parque Regional, mediante una mejor educación ambiental. 
- Preveer y hacer frente a un crecimiento de las actividades económicas, que favorezcan el dinamismo y la expansión económica del ámbito de planificación.

\section{LA COMPLEJA REALIDAD DE UN MEDIO FÍSICO EN TRANSFORMACIÓN}

La zona de estudio se localiza en el Sector Centro Occidental de la Cuenca o Depresión del Tajo, en la Cuenca o Fosa de Madrid. Desde el punto de vista metodológico, hemos partido del estudio topográfico de la zona, caracterizado por una topografía suave, ligeramente ondulada (constituida por lomas y vaguadas) que presenta cotas máximas de $690 \mathrm{~m}$. en Sevilla la Nueva y cotas mínimas de $555 \mathrm{~m}$. en la Vega del Río Alberche. Las mayores pendientes las localizamos en la mitad más occidental mientras que las menos pendientes corresponden a la zona de la divisoria de aguas, por donde discurre el curso fluvial del Río Guadarrama.

a. Análisis Geológico: La zona de estudio se incluye en una superficie erosionada, donde los elementos fluviales en ella insertos caracterizándose desde el punto de vista litoestratigráfico, por el dominio de materiales detríticos cenozoicos, han originado (desde finales del Terciario), un extenso y complejo sistema de terrazas que caracteriza el paisaje de cuencas fluviales de esta comarca (Se caracteriza por su heterogeneidad de sustratos). Fueron zonas sumergidas bajo el mar en su historia geológica reciente, y actualmente se encuentran llanos asociados a la depresión del Alberche y relieves de mesa. La variedad y singularidad de sustratos da lugar a un mosaico de paisajes muy heterogéneo, y más aún en la actualidad debido a ciertos usos del paisaje. Pueden encontrarse relieves de mesa con calizas y afloramientos de yeso, zonas de margas y lagunas endorreicas con acúmulos de sales. En la génesis climática de estas terrazas han inferido mecanismos de tipo estructural (litológico y técnico), elementos topográficos, hidrográficos e hidrodinámicos, meteorológicos...; ello ha originado que, en cada valle, las distintas terrazas tengan una peculiar caracterización. Así en niveles de acumulación fluvial, terrazas escalonadas y empotradas, terrazas climáticas y tectónicas, terrazas formadas por aportes de naturaleza química, etc. Los materiales cuaternarios constituyen la última serie estratigráfica presente en el área de estudio, la más corta de todas las analizadas y se caracterizan por estar constituidas por terrazas y fondos aluviales que se han formado por sedimentación fluvial de arenas, gravas (ambas se localizan en el fondo de los principales ríos y arroyos que atraviesan el término y a los glacis de la zona más occidental del territorio estudiado, Villamanta, zona centro de Navalcarnero y Sevilla la Nueva), limos y arcillas, quedando su extensión limitada a una estrecha franja a lo largo de los ríos y arroyos más importantes. De igual modo, aparecen Barrancos, no muy marcados, y vaguadas, en torno al Río Alberche y, en menor medida a arroyo Vegones.

b. Análisis Geomorfológico: La zona de estudio se localiza en el valle fluvial del río Guadarrama, este río tiene una marcada disimetría en las cercanías del área de estudio. Esta condición es muy común en la mayor parte de los cursos fluviales que se encuentran en la Cuenca de Madrid. Desde el punto de vista gemorfológico, la Cuenca de Madrid es una amplia cuenca de sedimentación intracontinetal, delimitada por fallas 
inversas de gran desarrollo, especialmente la de su borde noroeste. En el borde noroeste, dominan las suaves superficies y rampas que descienden escalonadamente hasta el Guadarrama, mientras que la zona sureste esta marcada por la presencia de parameras, con sus altas superficies complejas. Los valles del Arroyo Grande y del arroyo de Vegones encajados respecto a la superficie del área de estudio con la que se articulan, bien mediante escalonamiento de terrazas (vega del Guadarrama) o bien mediante escarpes o barrancos labrados en el sustrato arcósico (laderas vertientes del arroyo Grande), que en la mayor parte de las ocasiones responden a la expresión superficial de fallas que afectan al conjunto del relleno terciario de la Cuenca. Con todo ello podemos diferenciar doce formas geológicas claves: Barrancos, Cárcavas, Fondos de Valle, Navas, Campiñas, Taludes, Glacis, Páramos, Terrazas, Vaguadas y Escarpes.

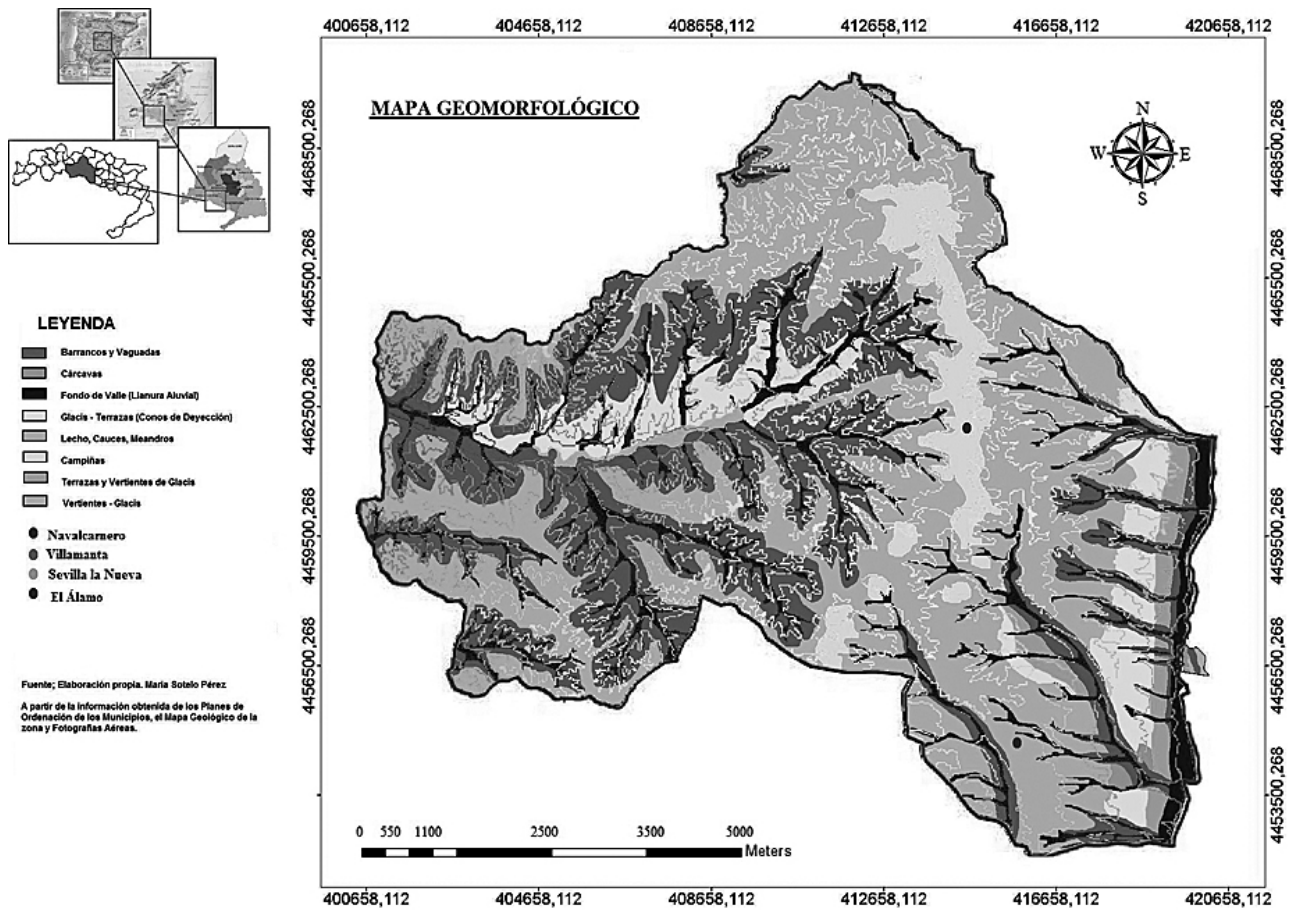

Fuente: Elaboración propia

c. Análisis Edafológico y Litológico: El suelo es el sistema complejo que se forma en la capa más superficial de la Tierra. En nuestro área de estudio predominan los suelos de interfluvios que se originan sobre las áreas más elevadas, en concreto la superficie de Navalcarnero, caracterizándose por una pendiente baja e incluso nula, dando lugar a suelos evolucionados; suelos de vertientes que Ocupan la mayor parte del municipio de Navalcarnero, en las áreas que enlazan el interfluvio con los fondos de valle y barrancos, dando lugar a suelos poco evolucionados; y suelos de fondos de valle, donde las pendientes son más bajas, dominando depósitos detríticos fluviales, con una importante cantidad de materiales finos y una evolución edáfica mayor. 

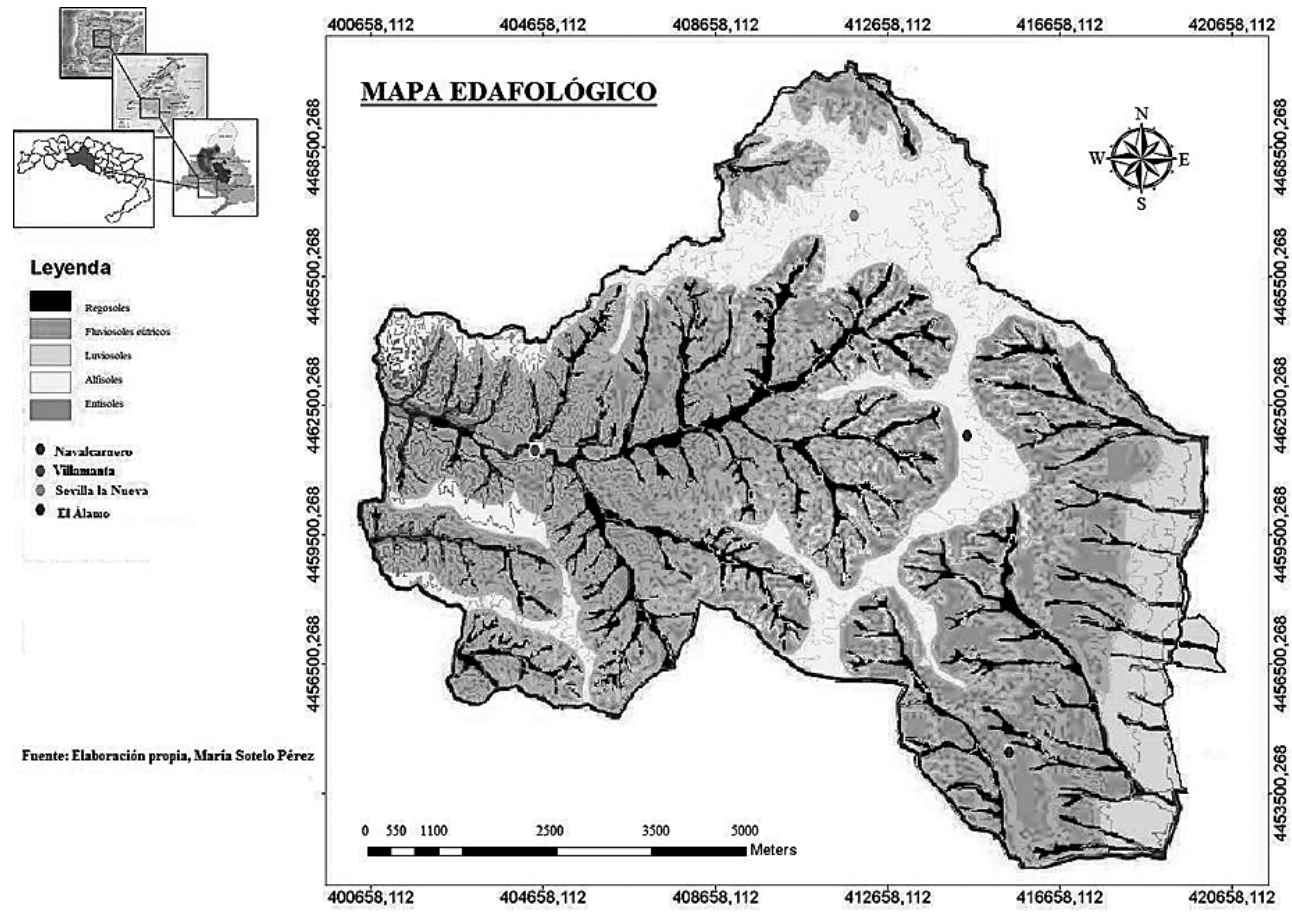

Fuente: Elaboración propia

Las asociaciones de suelos más importantes que se encuentran en la zona de estudio son: los Luvisoles, que es un tipo de suelo que se desarrolla dentro de las zonas con suaves pendientes o llanuras; los Regosoles; son suelos poco evolucionados con un escaso desarrollo genético; Fluviosoles, localizados en las vegas de los ríos; Entisoles, que son suelos de origen mineral sin horizontes de diagnóstico claramente desarrollados; $y$, Alfisoles, que se trata de suelos minerales que presentan un endopipedión argílico, nítrico o kándico. 

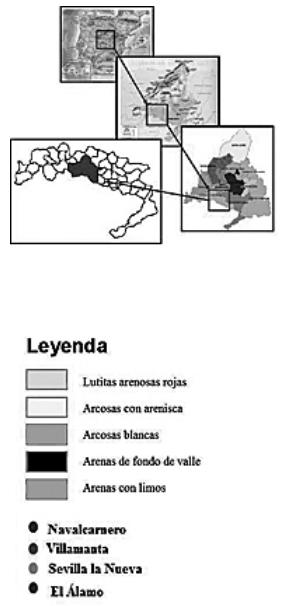

Fuente; Elaboraclón propla, María Sotelo Pérez.

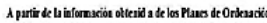

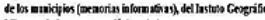

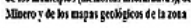

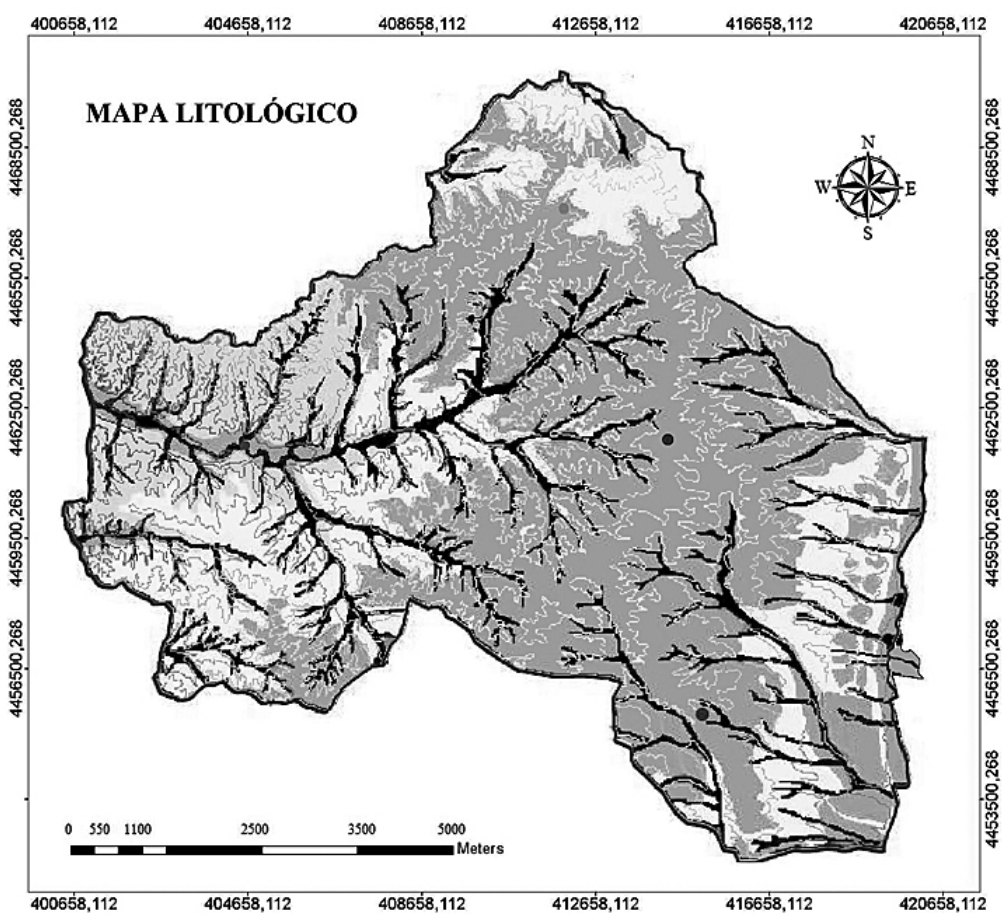

Fuente: Elaboración propia

d. Hidrología y climatología: Nuestra área de estudio se encuadra en la cuenca hidrográfica del Río Tajo, dentro de las cuencas del curso medio del Río Guadarrama y del Río Alberche. Ambos ríos configuran una doble divisoria de aguas a través de la cual se organiza y jerarquiza el conjunto de la red hidrográfica. Es importante tener en cuenta que nos encontramos en un espacio en el que abundan los arroyos; Arroyo de Castañuela, Arroyo de los Charcos, Arroyo de la Retamosa, Arroyo de la Fuente, caracterizados por su gran volumen de agua (estacional) en los meses de invierno y primavera... pero, también, se caracteriza por ser una zona de aguas subterráneas muy importante. De igual modo, tenemos que hacer referencia a que nuestra área de estudio encuentra inmersa en el sector central del Acuífero detrítico de Madrid. En cuanto a la climatología, nos encontramos ante un clima mediterráneo continentalizado, caracterizado por fuertes contrastes térmicos entre el invierno (inviernos fríos y lluviosos) y el verano (cálidos y secos) lo que confiere una gran singularidad a las actividades económicas de la zona, a su vegetación y a la tipología de los asentamientos.

e. Vegetación: La serie climatófila en la que se encuadra nuestra zona de estudio es la serie meso-supramediterránea guadarrámico-ibérica silicícola de la encina (Junípero oxycedri - Quercetum rotundifoliae), cuya vegetación potencial son los encinares silicícolas de ombroclima seco o subhúmedo inferior (PGOU de Navalcarnero). Dentro de esta serie, se corresponde a su faciación matritense sobre sustratos detríticos En los terrenos considerados, cuya vegetación potencial sería 
como ya se ha indicado un encinar, -caracterizado por poseer un sotobosque pobre en arbustos, retamares y lianas perennifoliolustrosas, siendo el árbol dominante la encina o carrasca, Quercus rotundifoliae Lam, tan solo se pueden encontrar actualmente algunas de las etapas seriales de dicha clímax, o dicho de otra manera, etapas regresivas producidas por la alteración antrópica del medio natural, siendo la más extendida las comunidades asentadas sobre cultivos de cereal en secano así como de Vid y olivos, junto con los pinares, pastizales y los cultivos de regadío.

\section{SISTEMA DE ASENTAMIENTOS}

\section{a. Población:}

\section{EVOLUCIÓN DE LA POBLACIÓN DESDE 1985 HASTA 2010}

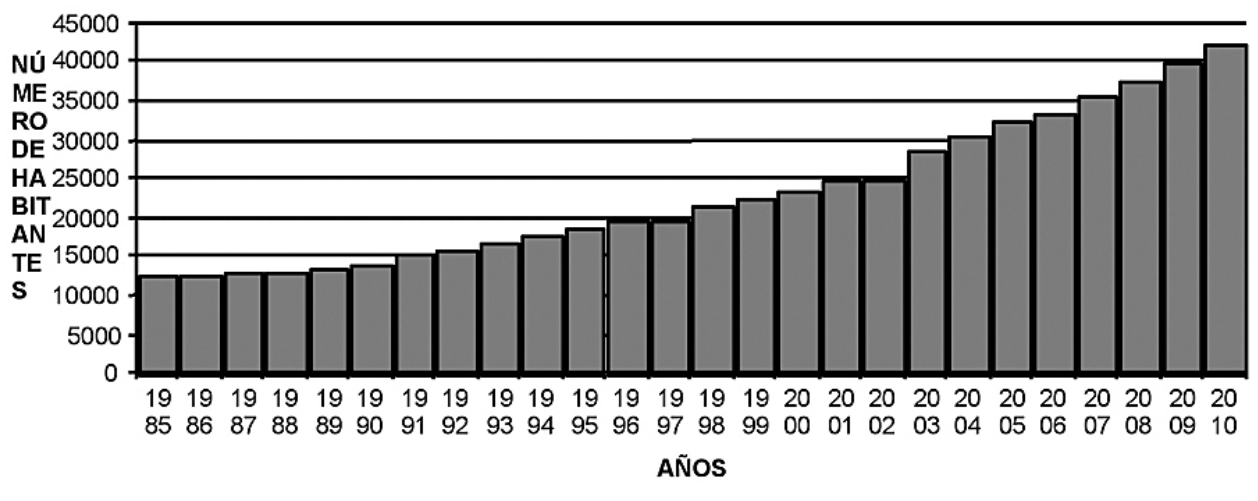

\begin{tabular}{|c|c|c|c|}
\hline Población de los municipios & Habitantes (2010) & Superficie (Km2) & Densidad \\
\hline El Álamo & 8.079 & 22,01 & 367,06 \\
\hline Navalcarnero & 23.115 & 100,89 & 229,11 \\
\hline Sevilla la Nueva & 8.578 & 24,74 & 346,73 \\
\hline Villamanta & 2.480 & 63,24 & 39,22 \\
\hline TOTAL & 42.252 & 210,88 & 200,36 \\
\hline
\end{tabular}

Fuente: Elaboración propia a partir de datos obtenidos de Estadísticas la Almudena

Tal y como podemos observar en el presente gráfico el crecimiento poblacional de nuestra zona de estudio ha seguido una tendencia exponencialmente progresiva desde 1985 hasta 2010. Todo esto es debido a que, dicho crecimiento poblacional, es producido (amén de por una mejora en la calidad de vida) a la facilidad de acceso vía carretera que ha provocado el aumento de la población vinculada a primera residencia (aunque también han aumentado las segunda residencia), y al incremento progresivo de la población inmigrante que accede a dicha zona por las actividades económicas vinculadas y con el hecho de que el precio del suelo y, por consiguiente, el precio de alquiler vs. compra de las viviendas es menor que en la corona metropolitana. 
Atendiendo a la superficie del territorio, no es una zona muy densamente poblada, en cuanto a primera residencia, pero progresivamente va incrementándose el número de individuos residentes en la zona por lo que la densidad de población se incrementa, y sobre todo, se encuadra en os núcleos municipales de cada uno de los municipios que lo configuran.
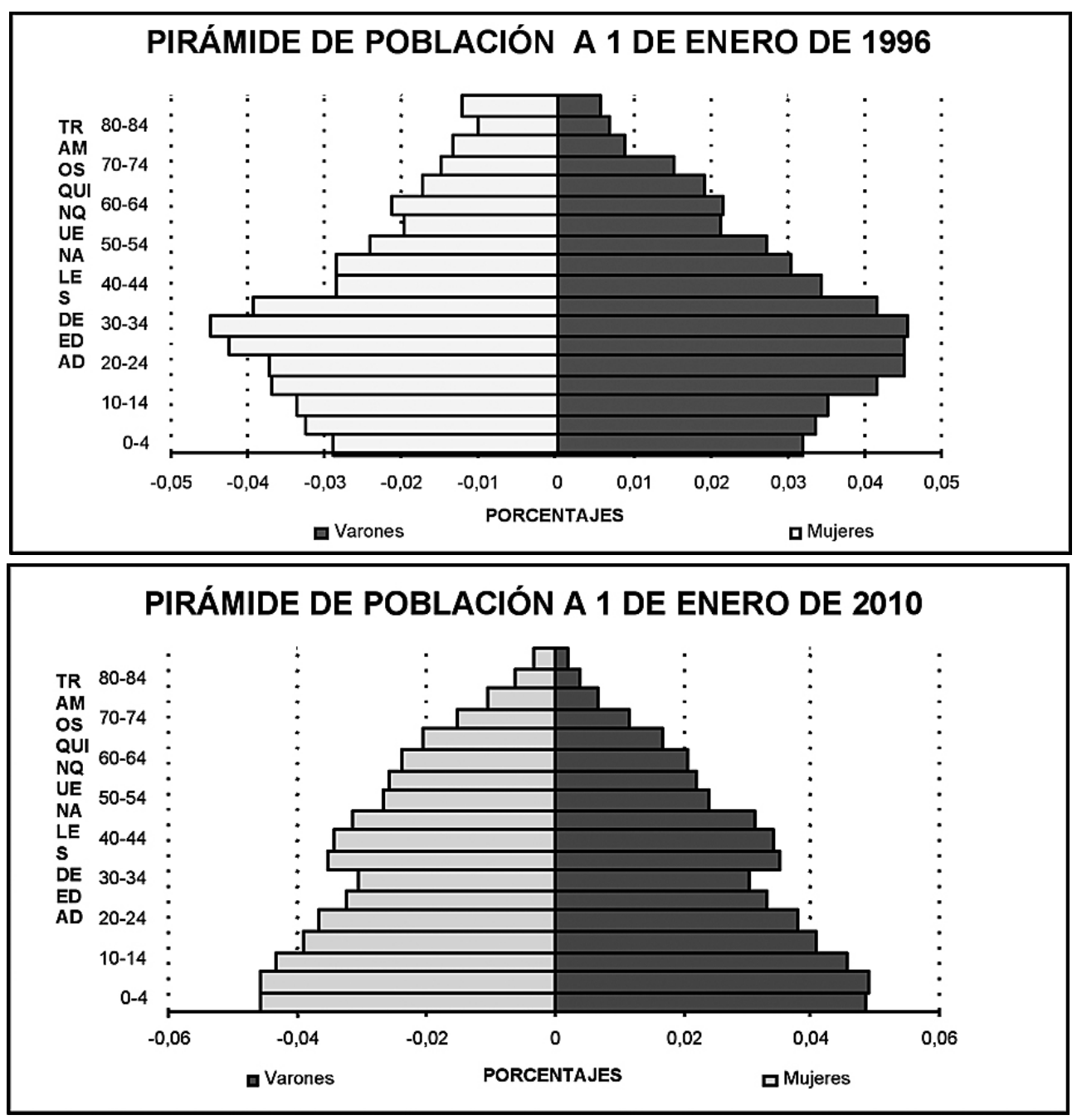

Fuente: Elaboración propia a partir de datos obtenidos del INE

La pirámide de población es una representación gráfica de la distribución de la población, en un instante determinado, atendiendo a la edad y el sexo. En cuanto al análisis que se deduce de los datos obtenidos de la población de la comarca estudiada, se observa que, se considera una población "joven" aunque la representación de la población menor de 15 años no llega a superar el 33\% del total de la población. Además, la tendencia de la estructura poblacional es a seguir rejuveneciéndose puesto que los efec- 
tivos de menores de 15 años son superiores a los de mayores de 65 años en más de cinco puntos. Podemos observar que la primera de las pirámides, del año 1996 es claramente regresiva, mientras que la pirámide de 2010 es progresiva pues la base de la pirámide es más pequeña que los intervalos de edad intermedios. La pirámide adquiere esta forma en poblaciones cuya natalidad ha descendido en los últimos años y es baja. El rasgo más llamativo de la pirámide del año 1996 es que la mayor concentración de población se da en las edades entre los 20 y los 45 años. Este grupo supone un casi la mitad de la población (43,8\%), lo que es producto de una intensa acogida de población, especialmente en las edades mayores de 25 años. Los grupos de edad de entre los 45 y los 65 años representan menos de la mitad que el grupo de edad anterior $(18,8 \%$ ) y también algo más que el grupo de edad superior, es decir, el de los de más de 65 años que representan un $12,6 \%$ del total de la población. Por debajo de los 15 años, las cohortes agrupan un número similar de personas, siendo la cohorte más destacada la comprendida entre los 15 y 19 años. Por lo tanto, nuestra zona de estudio presenta una estructura demográfica todavía joven, con grandes grupos en proceso de incorporarse a la edad activa desde el punto de vista laboral y reproductivo, además presenta un grado de juventud del $18,18 \%$, frente al 14,32\% que presenta la Comunidad de Madrid.

Por el contrario, al analizar la pirámide de población de 2010 podemos ver que esta tendencia de envejecimiento progresivo (pirámide regresiva de 1996) se ha ido invirtiendo y ahora nos encontramos con una pirámide progresiva, donde la base se ha ido ensanchando de manera muy significativa como consecuencia de esos movimientos migratorios expuestos anteriormente, no sólo por la facilidad incrementada de los movimientos pendulares entre nuestra zona de estudio y e centro metropolitano de Madrid, sino que también por e incremento de la población inmigrante que se ha asentado en este territorio tras ir llegando progresivamente desde los años 2000 (con la llamada de mano de obra inmigrante por parte de los empresarios) y que han ido asentando aquí su núcleo principal de residencia y de su familia. Todo ello asu vez a favorecido el incremento progresivo de los sistemas sanitarios, educativos y de vivienda (entre ellos la pública). Con todo ello podemos analizar que el grueso de la población se encuentra en las edades comprendidas entre los menores de 15 años hasta los 25 años de edad y los individuos con edades comprendidas entre los 40 y 45 años (mano de obra joven asociada a la llamada de esta y sus descendientes). Mientras que la pirámide se va estrechando hacia su punta, puesto que la población envejecida va siendo cada vez menor, porque en muchos casos los ancianos (al margen de la mortalidad) son enviados a residencias de ancianos a otros puntos fuera de esta comarca.

\section{b. Estructuración y vertebración del territorio:}

En lo referente a la estructuración del territorio y al sistema tradicional de núcleos de población nos encontramos ante cuatro núcleos base de población (población concentrada); correspondientes a los centros urbanos de cada uno de los municipios que configuran nuestra zona de estudio y, de forma aislada, algunos asentamientos dispersos en el territorio, correspondientes a urbanizaciones. Con todo ello, de forma meramente descriptiva, podemos delimitar un núcleo central o casco (casco antiguo), en torno a una plaza central (plaza mayor) sobre la cual comienza a extenderse de forma ordenada, bajo un plano irregular, el conjunto urbanístico de cada uno de los puntos centrales de edificación. En torno a este casco existe una zona de transición de manzanas con una mezcla de tipologías edi- 
ficatorias y parcelas de muy diferente tamaño. Al exterior de esta zona se despliega un crecimiento espontánea de urbanizaciones de origen de segunda vivienda, que han sido ejecutadas de forma independiente y en diferentes épocas, por lo cual la estructura viaria y la trama urbana es de forma irregular. Si nos centramos en los usos industriales, podemos observar claramente que se localizan mayoritariamente, en las afueras de los núcleos poblacionales, en torno a las vías de acceso o carreteras. De igual modo, son constatables los nuevos núcleos de segunda residencia, mayoritariamente, que configuran pequeñas urbanizaciones, "apartadas" de los centros o núcleos urbanos concentrados.

En cuanto a la clasificación de los usos del suelo, el territorio estudiado se caracteriza por la existencia de gran parte del espacio dedicado al uso urbano, tanto urbano como urbanizable y una densa extensión vinculada a suelo especial protegido estrechamente relacionado con la proximidad al Parque Regional del curso medio del río Guadarrama:

\begin{tabular}{|l|l|r|}
\hline & & \\
\hline Suelo urbano & Clasificación del suelo & $900,79 \mathrm{Ha}$. \\
\hline & Residencial Familiar & $108,94 \mathrm{Ha}$. \\
\hline & Servicios y equipamientos & $583,65 \mathrm{Ha}$. \\
\hline & Verde público & $103,9 \mathrm{Ha}$. \\
\hline Suelo Urbanizable & & $104,3 \mathrm{Ha}$. \\
\hline & Industrial & $660,54 \mathrm{Ha}$. \\
\hline & Residencial Familiar & $98,94 \mathrm{Ha}$. \\
\hline & Servicios y equipamientos & $353,4 \mathrm{Ha}$. \\
\hline \multirow{2}{*}{$\begin{array}{l}\text { Suelo para sistemas generales } \\
\text { Suelo especial protegido } \\
\text { Suelo no urbanizable común }\end{array}$} & Verde público & $103,9 \mathrm{Ha}$. \\
\cline { 2 - 3 } & & $104,3 \mathrm{Ha}$. \\
\cline { 2 - 3 } & & $873 \mathrm{Ha}$. \\
\cline { 2 - 3 } & & $14.473 \mathrm{Ha}$. \\
\hline
\end{tabular}

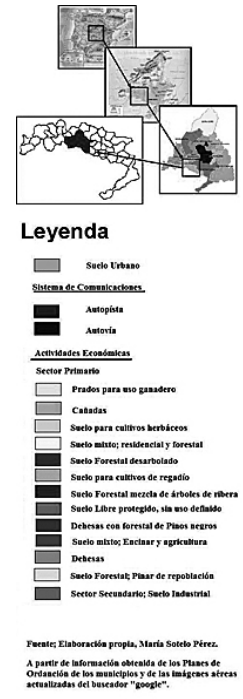

Fuente: Elaboración propia

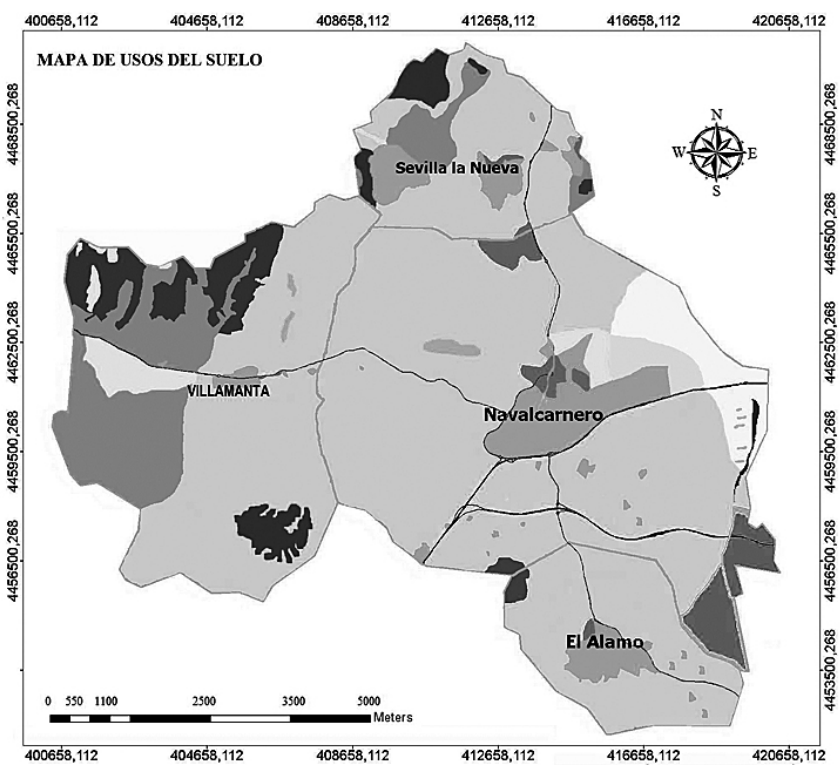

Observatorio Medioambiental 


\section{TRANSFORMACIONES ESPACIALES E INFRAESTRUCTURAS}

Sin lugar a dudas, nuestra zona de estudio ha presentado y presenta unas notabilísimas transformaciones espaciales, fruto de las nuevas infraestructuras. Detengámonos en su análisis

\section{a. Red de comunicaciones}

La zona de estudio está dotada de carreteras nacionales, autonómicas, autovías de peajes, autovías nacionales, caminos rurales... lo que favorece la comunicación de los distintos municipios que lo configuran con la corona metropolitana de Madrid, con el resto de municipios. vía carretera es tanto privada como pública. Mayoritariamente privada ya que los medios de transporte público de pasajeros exclusivamente, es algo precario (el de mercancías o mixto es superior) puesto que apenas se dispone de 37 autobuses y 25 taxis, para la comunicación interurbana con Madrid y con el resto de municipios colindantes; y para comunicación interna entre los municipios que configuran nuestra zona de estudio, es inferior y algo complicada por el entramado de calles estrechas e irregulares de los cascos antiguos de dichos municipios. En cuanto a la comunicación vía ferroviaria, hoy día, es inexistente pero el Plan Estratégico de Infraestructuras y Transportes (PEIT), recientemente presentado por el Ministerio de Fomento, contempla la próxima elaboración de un plan sectorial de actuaciones en la red de cercanías de Madrid, que cabe la posibilidad que pudiera extenderse a Navalcarnero, el cual es necesario concertar con el Gobierno de la Comunidad de Madrid.

\section{b. Red de servicios urbanos}

b.1. Abastecimiento de agua: En nuestra zona de estudio, el abastecimiento de agua se realiza de forma desigual y diferenciada, atendiendo al término municipal en el que nos situemos. En los casos de El Álamo y Villamanta (en menor medida Sevilla la Nueva y Navalcarnero), se abastecen actualmente de agua potable mediante pozos que están distribuidos por todo el territorio, por lo que el agua procede de los acuíferos existentes en la zona. Por el contrario, el término municipal de Navalcarnero se abastece en la actualidad del Canal de Isabel II (Aunque en el pasado la población se abastecía de pozos, en la actualidad, toda la población se abastece a través del Canal), concretamente del embalse de Valmayor, a través de una arteria general (después de discurrir por los municipios de Villanueva del Pardillo, Villanueva de la Cañada y Brunete, finaliza en Navalcarnero).

b.2. Saneamiento y depuración: Actualmente el municipio de Navalcarnero dispone de una red de saneamiento unitario que conducen a dos colectores principales, uno paralelo al arroyo de los Vegones y otro al sur del municipio en el margen oriental del arroyo de las Vegas (depuración de aguas de EDAR) que se encarga de depurar las aguas de los términos municipales de El Álamo, Navalcarnero, Villamanta, Batres y Arroyomolinos.

\section{c. Redes de equipamientos sociales}

Equipamientos municipales vinculados al Estado del Bienestar. Los municipios que configuran el área de estudio se caracterizan por estar equipados con centros Administrativos, educativos y deportivos en cada uno de los municipios, pero a lo 
que se refiere a servicios sanitarios, tan sólo Navalcarnero cuenta con centro de salud. De igual modo, Navalcarnero cuenta con museos y centros de ocio especializados en el turismo.

\section{LOS ESPACIOS NATURALES PROTEGIDOS}

El área de estudio se encuadra dentro del Parque Regional del Curso Medio del Río Guadarrama, espacio natural protegido de la Comunidad de Madrid, que se configura como una larga franja entorno al Río Guadarrama y sus afluentes. El Parque ocupa una superficie de aproximadamente 22.000 hectáreas (desde el embalse de Las Nieves hasta el embalse de Batres, en la provincia de Toledo). El Parque ocupa un extensión de 2.000 hectáreas en el término municipal de Navalcarnero, 150 hectáreas en Sevilla la Nueva y 300 hectáreas del municipio de El Álamo.

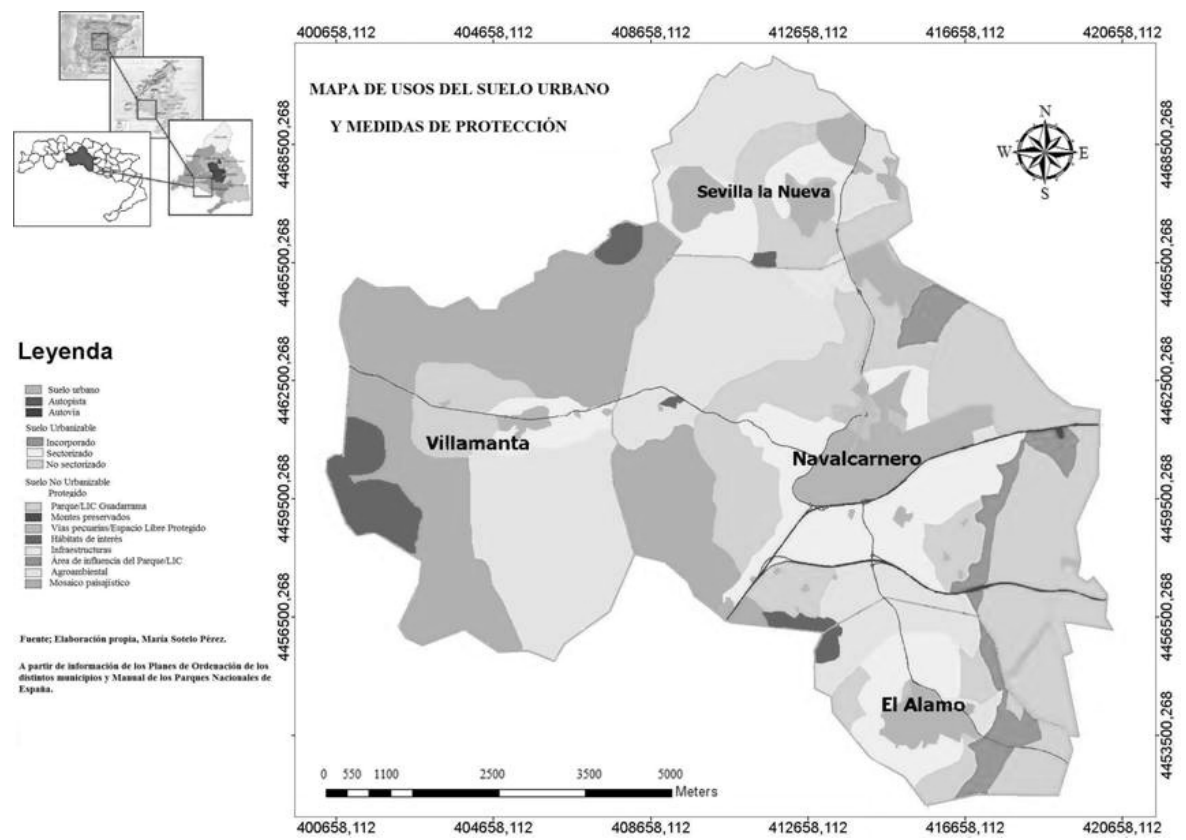

Fuente: Elaboración propia

El Parque, como espacio natural protegido, posee un conjunto de singularidades geológicas, geomorfológicas, paisajísticas, hidrográficas, faunísticas y botánicas que han favorecido la inclusión de medidas de protección considerando el área de estudio como una Zona Especial de Protección de Aves (ZEPA), parajes pintorescos, mosaicos paisajísticos y Lugares de Interés Comunitario (LIC), entorno a la rivera del Río Guadarrama, encuadrando toda la zona de monte de nuestro área de estudio bajo la protección de la Ley Forestal de la Comunidad de Madrid. Puesto que las menazas de transformación y la presión ejercida por el hombre en el medio han originado la necesidad de proteger y preservar esta zona de alto valor. 


\section{UNIDADES AMBIENTALES}

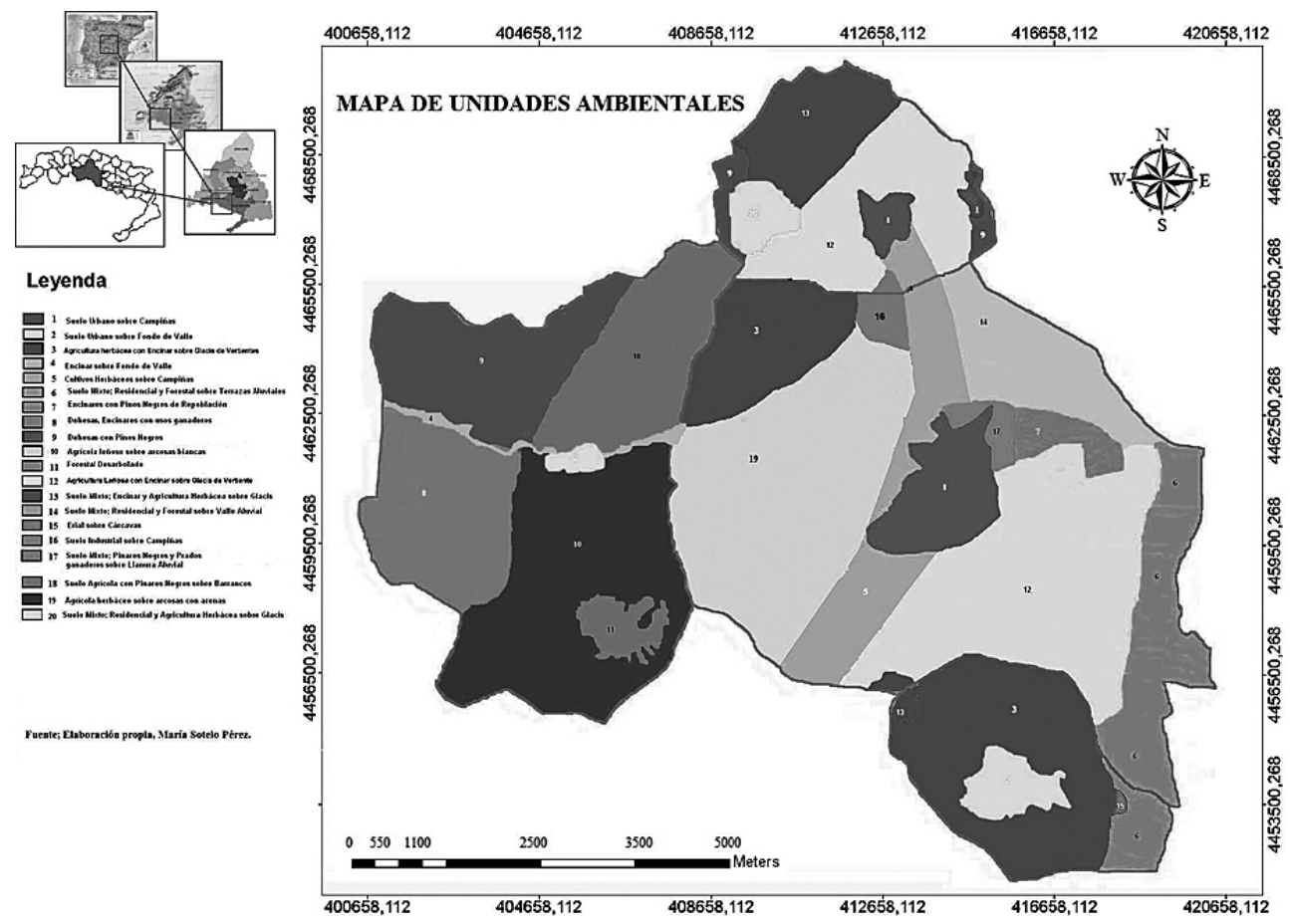

Fuente: Elaboración propia

7. VALORACIÓN DE LAS UNIDADES AMBIENTALES: COMPONENTES BIÓTICOS, ABIÓTICOS, INFRAESTRUCTURAS Y ASENTAMIENTOS QUE PODEMOS LOCALIZAR EN LAS DISTINTAS UNIDADES AMBIENTALES ANALIZADAS.

\begin{tabular}{|c|l|l|l|}
\hline$\underline{\text { UNIDAD AMBIENTAL }}$ & $\underline{\text { ASPECTOS BIÓTICOS }}$ & $\underline{\underline{\text { ASPECOS ABIÓTICOS }}}$ & $\underline{\underline{\text { INFRAESTRUCTURAS Y }}}$ \\
\hline $\begin{array}{c}\text { Suelo urbano sobre } \\
\text { Campiñas }\end{array}$ & $\begin{array}{l}\text { Cultivos herbáceos: cente- } \\
\text { no, trigo y beza. } \\
\text { Alguna encina u olivo aisla- } \\
\text { do entorno al centro urbano. }\end{array}$ & $\begin{array}{l}\text { Atendiendo a la litología, } \\
\text { encontramos Arcosas con } \\
\text { arenisca y arcosas blancas. } \\
\text { La edafología predominante } \\
\text { los Alfisoles. } \\
\text { En cuanto a la geomorfolo- } \\
\text { gía encontramos Campiñas y y } \\
\text { Glacis de vertiente. }\end{array}$ & $\begin{array}{l}\text { Autopista y Autovía. Lo que } \\
\text { favorece la comunicación con } \\
\text { el centro de la metrópoli y la } \\
\text { conectividad entre los distin- } \\
\text { tos núcleos municipales. } \\
\text { Numerosas carreteras y cami- } \\
\text { nos.Cañada en el propio } \\
\text { Núcleo Urbano de } \\
\text { Navalcarnero. Núcleo Urbano } \\
\text { de Navalcarnero.Núcleo } \\
\text { Urbano de Sevilla la Nueva. } \\
\text { Zona industrial. Pequeños } \\
\text { polígonos. }\end{array}$ \\
\hline
\end{tabular}




\begin{tabular}{|c|c|c|c|}
\hline UNIDAD AMBIENTAL & ASPECTOS BIÓTICOS & $\underline{\text { ASPECOS ABIÓTICOS }}$ & $\frac{\text { INFRAESTRUCTURAS Y }}{\underline{\text { ASENTAMIENTOS }}}$ \\
\hline $\begin{array}{l}\text { UA2. } \\
\text { Suelo Urbano sobre Fondo } \\
\text { de Valle }\end{array}$ & $\begin{array}{l}\text { Cultivos hortícolas de } \\
\text { regadíos; lechugas, acelgas } \\
\text { y coliflor. } \\
\text { Cultivos herbáceos de } \\
\text { trigo, garbanzo, cebada y } \\
\text { avena. } \\
\text { Cultivos leñosos; Jaras y } \\
\text { Tomillos. }\end{array}$ & $\begin{array}{l}\text { La edafología existente está } \\
\text { configurada por Regosoles y } \\
\text { Fluviosoles eútricos. } \\
\text { En cuanto a la geomorfología, } \\
\text { predominan de forma abun- } \\
\text { dante los Lechos y cauce, } \\
\text { Fondo de Valle, Glacis y terra- } \\
\text { zas (cono de deyección) y } \\
\text { Glacis de vertientes } \\
\text { La litología son Arenas con } \\
\text { limos, Arenas de fondo de } \\
\text { valle, Lutitas arenosas rojas, } \\
\text { Arcosas Blancas. }\end{array}$ & $\begin{array}{l}\text { Autovía. } \\
\text { Numerosas carreteras y } \\
\text { caminos. } \\
\text { Núcleo Urbano de } \\
\text { Villamanta y el Álamo. } \\
\text { Zona de polígonos indus- } \\
\text { triales. }\end{array}$ \\
\hline $\begin{array}{c}\text { UA3. } \\
\text { Agricultura herbácea con } \\
\text { Encinar sobre Glacis de } \\
\text { Vertiente }\end{array}$ & $\begin{array}{l}\text { Forestal y cultivos leñosos; } \\
\text { encinares. Cultivos hortí- } \\
\text { colas de regadío como } \\
\text { lechugas, acelgas y coliflo- } \\
\text { res. } \\
\text { Árboles de ribera. } \\
\text { Zona agroambiental. }\end{array}$ & $\begin{array}{l}\text { Alfisoles, Regosoles y } \\
\text { Fluviosoles eútricos. } \\
\text { Lechos y cauce, Fondo de } \\
\text { Valle, Glacis y terrazas (cono } \\
\text { de deyección) y Glacis de } \\
\text { vertientes. } \\
\text { Arenas con limos, Arenas de } \\
\text { fondo de valle, Lutitas are- } \\
\text { nosas rojas, Arcosas Blancas. } \\
\text { Barrancos y vaguadas. }\end{array}$ & $\begin{array}{l}\text { Mosaico paisajístico } \\
\text { (Ordenación Urbana). } \\
\text { Acceso a la Autovía en el } \\
\text { nudo sur. } \\
\text { Atravesada por carreteras } \\
\text { secundarias. de uso indus- } \\
\text { trial. Pequeños polígonos. } \\
\text { Núcleo urbano de El } \\
\text { Álamo. }\end{array}$ \\
\hline $\begin{array}{l}\text { UA4. } \\
\text { Encinar sobre Fondo de } \\
\text { Valle. }\end{array}$ & $\begin{array}{l}\text { Cultivos de regadío, sobre } \\
\text { todo hortalizas. } \\
\text { Membrilleros y almendros. } \\
\text { Dehesas, Encinares. } \\
\text { Prados para usos ganaderos. } \\
\text { Ganadería porcina. } \\
\text { Pinares negros de repo- } \\
\text { blación. }\end{array}$ & $\begin{array}{l}\text { Fondo de Valle, Regosoles y } \\
\text { entisoles. Fluviosoles eútri- } \\
\text { cos. Arenas de fondo de valle }\end{array}$ & $\begin{array}{l}\text { La autovía se ha realizado } \\
\text { sobre el propio Fondeo } \\
\text { Aluvial por lo que muestra } \\
\text { el recorrido de la carretera. } \\
\text { Núcleo urbano de } \\
\text { Villamanta. }\end{array}$ \\
\hline $\begin{array}{c}\text { UA5. } \\
\text { Cultivos herbáceos sobre } \\
\text { Campiñas. }\end{array}$ & $\begin{array}{l}\text { Pinares negros, dispersos } \\
\text { por el territorio. } \\
\text { Cultivos leñosos aislados } \\
\text { de Encinas. } \\
\text { Cultivos herbáceos, sobre } \\
\text { todo de trigo y cebada. }\end{array}$ & $\begin{array}{l}\text { Campiñas. } \\
\text { Alfisoles y fluviosoles eútri- } \\
\text { cos con la presencia aislada } \\
\text { de regosoles. } \\
\text { Vertientes y Glacis, con pre- } \\
\text { sencia de Llanuras aluviales. } \\
\text { Arcosas bancas y presencia } \\
\text { de arenas de fondo de valle. }\end{array}$ & $\begin{array}{l}\text { Núcleos urbanos de } \\
\text { Navalcarnero y Sevilla la } \\
\text { Nueva. } \\
\text { Núcleos de población aisla- } \\
\text { dos, sobre todo urbanizacio- } \\
\text { nes de nueva construcción. } \\
\text { Carreteras secundarias. } \\
\text { Suelo industrial, polígonos } \\
\text { industriales. }\end{array}$ \\
\hline $\begin{array}{c}\text { UA6. } \\
\text { Suelo Mixto; residencial y } \\
\text { forestal sobre Terrazas }\end{array}$ & $\begin{array}{l}\text { Cultivos de regadío, peque- } \\
\text { ñas plantaciones de mem- } \\
\text { brillos y árboles de ribera } \\
\text { (entre los más destacados, } \\
\text { algunas choperas). } \\
\text { Ganado ovino, vinculado a } \\
\text { la cañada. } \\
\text { Zona de pastos. } \\
\text { Pinos negros de repoblación }\end{array}$ & $\begin{array}{l}\text { Luviosoles y regosoles. } \\
\text { Llanura aluvial, terrazas, gla- } \\
\text { cis-terrazas (conos de deyec- } \\
\text { ción) y barrancos. Arenas } \\
\text { sobre limos, arenas de fondo } \\
\text { de valle y arcosas con arenisca }\end{array}$ & $\begin{array}{l}\text { Suelo industrial. Parque } \\
\text { Regional, zona protegida } \\
\text { (LIC). Residencias y peque- } \\
\text { ñas urbanizaciones. Zona } \\
\text { especial de protección de } \\
\text { aves (ZEPA). Cañada, tran- } \\
\text { sito de ganado ovino funda- } \\
\text { mentalmente. }\end{array}$ \\
\hline $\begin{array}{l}\text { UA7. Encinares con Pinos } \\
\text { Negros de Repoblación }\end{array}$ & $\begin{array}{l}\text { Abundan los pinos silves- } \\
\text { tres y pinos negros de } \\
\text { repoblación. } \\
\text { Cultivos herbáceos de } \\
\text { Encinares. }\end{array}$ & $\begin{array}{l}\text { Regosoles y fluviosoles. } \\
\text { Fondos de valle, glacis de } \\
\text { vertiente y proximidad de los } \\
\text { barrancos. } \\
\text { Arcosas blancas y arcosas } \\
\text { con areniscas }\end{array}$ & $\begin{array}{l}\text { Carreteras secundarias y } \\
\text { caminos. } \\
\text { Zona de influencia del } \\
\text { Parque Regional, atendien- } \\
\text { do a la Ordenación Urbana. } \\
\text { Proximidad al Núcleo urba- } \\
\text { no de Navalcarnero. }\end{array}$ \\
\hline
\end{tabular}




\begin{tabular}{|c|c|c|c|}
\hline$\underline{\text { UNIDAD AMBIENTAL }}$ & ASPECTOS BIÓTICOS & ASPECOS ABIÓTICOS & $\frac{\text { INFRAESTRUCTURAS Y }}{\underline{\text { ASENTAMIENTOS }}}$ \\
\hline $\begin{array}{c}\text { UA8. } \\
\text { Dehesas; Encinares con } \\
\text { usos ganaderos }\end{array}$ & $\begin{array}{l}\text { Fundamentalmente, es una } \\
\text { dehesa configurada por } \\
\text { Dehesas de Encinares, pero } \\
\text { también encontramos } \\
\text { Prados para el pasto del } \\
\text { ganado, principalmente } \\
\text { ovino. De igual modo } \\
\text { podemos encontrar árboles } \\
\text { de almendros en pequeñas } \\
\text { fincas, y algún espécimen } \\
\text { de pino silvestre. }\end{array}$ & \begin{tabular}{|l} 
Entisoles, alfisoles, \\
Fluviosoles y Regosoles. \\
Barrancos, Fondos de Valle y \\
glacis de vertiente. Lutitas \\
arenosas rojas, Arcosas con \\
areniscas, Arcosas con limos \\
y Arcosas de Fondo de valle.
\end{tabular} & $\begin{array}{l}\text { Fundamentalmente encon- } \\
\text { tramos numerosos caminos } \\
\text { ya que, al tratarse de una } \\
\text { zona ganadera y agrícola, } \\
\text { los caminos son el mejor y, } \\
\text { tal vez único, acceso a las } \\
\text { fincas. Atendiendo a la } \\
\text { Ordenación Urbana, encon- } \\
\text { tramos un hábitat de interés } \\
\text { paisajístico. }\end{array}$ \\
\hline $\begin{array}{c}\text { UA9. } \\
\text { Dehesas con Pinos negros. }\end{array}$ & $\begin{array}{l}\text { Encinas, zona de dehesa, } \\
\text { vinculada a la ganadería por- } \\
\text { cina y, en menor medida, } \\
\text { ovina. Forestales de pinos } \\
\text { negros y pinos silvestres } \\
\text { (principalmente de repobla- } \\
\text { ción) y Cultivos de regadío }\end{array}$ & $\begin{array}{l}\text { Entisoles, alfisoles, } \\
\text { Fluviosoles y Regosoles. } \\
\text { Barrancos, Fondos de Valle, } \\
\text { terrazas-glacis (cono de deyec- } \\
\text { ción) y glacis de vertiente }\end{array}$ & $\begin{array}{l}\text { Caminos que permiten el } \\
\text { acceso a las fincas y a las } \\
\text { zonas forestales. Mosaico } \\
\text { paisajístico (atendiendo a la } \\
\text { Ordenación Urbana). } \\
\text { Encontramos alguna peque- } \\
\text { ña residencia secundaria y } \\
\text { una pequeña urbanización. }\end{array}$ \\
\hline $\begin{array}{c}\text { UA10. } \\
\text { Agrícola leñosa sobre } \\
\text { Arcosas Blancas. }\end{array}$ & $\begin{array}{l}\text { Cultivos leñosos de viñedos } \\
\text { de denominación de origen } \\
\text { de Madrid y algunos olivos. } \\
\text { Cultivos herbáceos, sobre } \\
\text { todo de trigo y cebada. } \\
\text { También encontramos } \\
\text { pequeños cultivos de rega- } \\
\text { dío como los membrillos y } \\
\text { alguna pequeña chopera }\end{array}$ & $\begin{array}{l}\text { Campiñas. Alfisoles y fluvio- } \\
\text { soles eútricos con la presen- } \\
\text { cia aislada de regosoles. } \\
\text { Vertientes y Glacis, con pre- } \\
\text { sencia de Llanuras aluviales. } \\
\text { Arcosas bancas y presencia } \\
\text { de arenas de fondo de valle. }\end{array}$ & $\begin{array}{l}\text { Se localizan caminos pecua- } \\
\text { rios y pequeñas carreteras } \\
\text { secundarias que interrela- } \\
\text { cionan a los cuatro munici- } \\
\text { pios estudiados con pueblos } \\
\text { limítrofes y con Toledo. }\end{array}$ \\
\hline $\begin{array}{c}\text { UA11. } \\
\text { Forestal desarbolado. }\end{array}$ & Matorral. & $\begin{array}{l}\text { Entisoles, alfisoles, } \\
\text { Fluviosoles y Regosoles. } \\
\text { Barrancos, Fondos de Valle, } \\
\text { terrazas-glacis (cono de deyec- } \\
\text { ción) y glacis de vertiente. }\end{array}$ & $\begin{array}{l}\text { Encontramos numerosos } \\
\text { caminos rurales para acceder } \\
\text { a la zona de cultivos. Núcleos } \\
\text { urbanos dispersos y pequeñas } \\
\text { urbanizaciones de nueva } \\
\text { construcción. Encontramos la } \\
\text { carretera nacional }\end{array}$ \\
\hline $\begin{array}{c}\text { UA12. } \\
\text { Agricultura leñosa con } \\
\text { Encinar, sobre Glacis de } \\
\text { Vertiente. }\end{array}$ & $\begin{array}{l}\text { Encinas, zona de dehesa, } \\
\text { vinculada a la ganadería } \\
\text { porcina y, en menor medida, } \\
\text { ovina. Forestales de pinos } \\
\text { negros y pinos silvestres } \\
\text { (principalmente de repobla- } \\
\text { ción) y Cultivos de regadío }\end{array}$ & $\begin{array}{l}\text { Atendiendo a la litología, } \\
\text { encontramos Arcosas con are- } \\
\text { nisca y arcosas blancas. La } \\
\text { edafología predominante los } \\
\text { Alfisoles. En cuanto a la geo- } \\
\text { morfología encontramos } \\
\text { Campiñas y Glacis de vertiente }\end{array}$ & $\begin{array}{l}\text { Autopista y Autovía. Lo } \\
\text { que favorece la comunica- } \\
\text { ción con el centro de la } \\
\text { metrópoli y la conectividad } \\
\text { entre los distintos núcleos } \\
\text { municipales. Numerosas } \\
\text { carreteras y caminos. } \\
\text { Cañada en el propio. } \\
\text { Proximidad al Núcleo } \\
\text { Urbano de Navalcarnero. } \\
\text { Núcleo Urbano de El } \\
\text { Álamo y Sevilla la Nueva. }\end{array}$ \\
\hline $\begin{array}{c}\text { UA13. } \\
\text { Encinares y Agricultura } \\
\text { herbácea sobre Glacis. }\end{array}$ & $\begin{array}{l}\text { Forestal y cultivos leñosos; } \\
\text { encinares. Cultivos hortí- } \\
\text { colas de regadío como } \\
\text { lechugas, acelgas y coliflo- } \\
\text { res. Árboles de ribera. } \\
\text { Zona agroambiental. }\end{array}$ & $\begin{array}{l}\text { Alfisoles, Regosoles y } \\
\text { Fluviosoles eútricos. Lechos y } \\
\text { cauce, Fondo de Valle, Glacis } \\
\text { y terrazas (cono de deyec- } \\
\text { ción) y Glacis de vertientes. } \\
\text { Arenas con limos, Arenas de } \\
\text { fondo de valle, Lutitas areno- } \\
\text { sas rojas, Arcosas Blancas. } \\
\text { Barrancos y vaguadas. }\end{array}$ & $\begin{array}{l}\text { Mosaico paisajístico } \\
\text { (Ordenación Urbana). } \\
\text { Acceso a la Autovía en el } \\
\text { nudo sur. Atravesada por } \\
\text { carreteras secundarias. }\end{array}$ \\
\hline
\end{tabular}




\begin{tabular}{|c|c|c|c|}
\hline$\underline{\text { UNIDAD AMBIENTAL }}$ & ASPECTOS BIÓTICOS & ASPECOS ABIÓTICOS & $\frac{\text { INFRAESTRUCTURAS Y }}{\text { ASENTAMIENTOS }}$ \\
\hline $\begin{array}{l}\text { UA14. Suelo mixto; resi- } \\
\text { dencial y forestal sobre } \\
\text { Valle Aluvial }\end{array}$ & $\begin{array}{l}\text { Pinares negros, dispersos } \\
\text { por el territorio. Cultivos } \\
\text { leñosos aislados de Encinas. } \\
\text { Cultivos herbáceos, sobre } \\
\text { todo de trigo y cebada. }\end{array}$ & $\begin{array}{l}\text { Campiñas. Alfisoles y flu- } \\
\text { viosoles eútricos con la pre- } \\
\text { sencia aislada de regosoles. } \\
\text { Vertientes y Glacis, con pre- } \\
\text { sencia de Llanuras aluviales. } \\
\text { Arcosas bancas y presencia } \\
\text { de arenas de fondo de valle. }\end{array}$ & $\begin{array}{l}\text { Proximidad a los núcleos } \\
\text { urbanos de Navalcarnero y } \\
\text { Sevilla la Nueva. Núcleos } \\
\text { de población aislados, sobre } \\
\text { todo urbanizaciones de } \\
\text { nueva construcción. } \\
\text { Carreteras secundarias. }\end{array}$ \\
\hline $\begin{array}{l}\text { UA15. Erial sobre } \\
\text { Cárcavas }\end{array}$ & $\begin{array}{l}\text { Matorral. Paso de ganado } \\
\text { ovino por la zona de cañada }\end{array}$ & $\begin{array}{l}\text { Cárcavas, Fondos de Valle y } \\
\text { Barrancos. Renas con limos, } \\
\text { Arenas sobre Fondo de Valle } \\
\text { y Arcosas con arenisca. } \\
\text { Regosoles, luviosoles y } \\
\text { Fluviosoles eútricos. }\end{array}$ & $\begin{array}{l}\text { Acceso a la Autovía en el } \\
\text { nudo sur. Atravesada princi- } \\
\text { palmente, por una cañada. } \\
\text { Proximidad al Núcleo urba- } \\
\text { no de El Álamo. }\end{array}$ \\
\hline $\begin{array}{l}\text { UA16. Suelo industrial } \\
\text { sobre Campiñas }\end{array}$ & $\begin{array}{l}\text { Pequeños árboles platane- } \\
\text { ros de adorno y algún } \\
\text { ejemplar de encina y olivo } \\
\text { (pero aislado). }\end{array}$ & $\begin{array}{l}\text { Alfisoles, Regosoles y } \\
\text { Fluviosoles eútricos. } \\
\text { Campiñas. Arenas con limos, } \\
\text { Arenas de fondo de valle, } \\
\text { Lutitas arenosas rojas, } \\
\text { Arcosas Blancas. }\end{array}$ & $\begin{array}{l}\text { Acceso a la Autovía en el } \\
\text { nudo sur. Atravesada por } \\
\text { carreteras secundarias. } \\
\text { Zonas de uso industrial. } \\
\text { Pequeños polígonos. }\end{array}$ \\
\hline $\begin{array}{l}\text { UA17. Pinares negros y } \\
\text { prados ganaderos sobre } \\
\text { Llanura Aluvial. }\end{array}$ & $\begin{array}{l}\text { Abundan los pinos negros } \\
\text { y los pinos silvestres de } \\
\text { repoblación. Cultivos her- } \\
\text { báceos de Encinares. }\end{array}$ & $\begin{array}{l}\text { Atendiendo a la litología, } \\
\text { encontramos Arcosas con } \\
\text { arenisca y arcosas blancas. } \\
\text { La edafología predominan- } \\
\text { te los Alfisoles. En cuanto } \\
\text { a la geomorfología encon- } \\
\text { tramos Campiñas y Glacis } \\
\text { de vertiente. }\end{array}$ & $\begin{array}{l}\text { Autopista y Autovía. Lo } \\
\text { que favorece la comunica- } \\
\text { ción con el centro de la } \\
\text { metrópoli y la conectividad } \\
\text { entre los distintos núcleos } \\
\text { municipales. Numerosas } \\
\text { carreteras y caminos. } \\
\text { Proximidad al núcleo } \\
\text { Urbano de Navalcarnero. }\end{array}$ \\
\hline $\begin{array}{l}\text { UA18. Suelo Agrícola con } \\
\text { Pinares Negros sobre } \\
\text { Barrancos. }\end{array}$ & $\begin{array}{l}\text { Forestales de pinos negros } \\
\text { y pinos silvestres (princi- } \\
\text { palmente de repoblación) y } \\
\text { Cultivos de regadío }\end{array}$ & $\begin{array}{l}\text { Entisoles, alfisoles, } \\
\text { Fluviosoles y Regosoles. } \\
\text { Barrancos, Fondos de Valle, } \\
\text { terrazas-glacis (cono de deyec- } \\
\text { ción) y glacis de vertiente. }\end{array}$ & $\begin{array}{l}\text { Caminos que permiten el } \\
\text { acceso a las fincas y a las } \\
\text { zonas forestales. Mosaico } \\
\text { paisajístico (atendiendo a la } \\
\text { Ordenación Urbana). } \\
\text { Encontramos alguna peque- } \\
\text { ña residencia secundaria y } \\
\text { una pequeña urbanización. }\end{array}$ \\
\hline $\begin{array}{l}\text { UA19. Agrícola herbáceo } \\
\text { sobre arcosas con arenas. }\end{array}$ & $\begin{array}{l}\text { Forestal y cultivos herbá- } \\
\text { ceos, sobre todo cultivos } \\
\text { hortícolas de regadío como } \\
\text { lechugas, acelgas y coliflo- } \\
\text { res, y sobre todo almen- } \\
\text { dros. Árboles de ribera. } \\
\text { Zona agroambiental. } \\
\text { También encontramos } \\
\text { algunos cultivos leñosos } \\
\text { como las encinas. }\end{array}$ & $\begin{array}{l}\text { Alfisoles, Regosoles y } \\
\text { Fluviosoles eútricos. Lechos } \\
\text { y cauce, Fondo de Valle, } \\
\text { Glacis y terrazas (cono de } \\
\text { deyección) y Glacis de ver- } \\
\text { tientes. Arenas con limos, } \\
\text { Arenas de fondo de valle, } \\
\text { Lutitas arenosas rojas, } \\
\text { Arcosas Blancas. Barrancos } \\
\text { y vaguadas. }\end{array}$ & $\begin{array}{l}\text { Proximidad al núcleo urba- } \\
\text { no de Navalcarnero. } \\
\text { Núcleos urbanos dispersos } \\
\text { y pequeñas urbanizaciones } \\
\text { de nueva construcción. } \\
\text { Encontramos la carretera } \\
\text { nacional. Transepto de la } \\
\text { Autopísta y la Autovía. }\end{array}$ \\
\hline $\begin{array}{l}\text { UA20. Suelo mixto: resi- } \\
\text { dencial y agricultura her- } \\
\text { bácea sobre Glacis. }\end{array}$ & $\begin{array}{l}\text { Cultivos herbáceos de } \\
\text { Almendros, membrillos, } \\
\text { lechugas y tomates. Árbo- } \\
\text { les de ribera. Zona agro- } \\
\text { ambiental. }\end{array}$ & $\begin{array}{l}\text { Lechos y cauce, Fondo de } \\
\text { Valle, Glacis y terrazas } \\
\text { (cono de deyección) y Glacis } \\
\text { de vertientes, Barrancos y } \\
\text { vaguadas. Alfisoles y fluvio- } \\
\text { soles eútricos con la presen- } \\
\text { cia aislada de regosoles. } \\
\text { Vertientes y Glacis, con pre- } \\
\text { sencia de Llanuras aluviales. } \\
\text { Arcosas bancas y arenas de } \\
\text { fondo de valle. }\end{array}$ & $\begin{array}{l}\text { Se localizan caminos } \\
\text { pecuarios y pequeñas carre- } \\
\text { teras secundarias que inte- } \\
\text { rrelacionan a los cuatro } \\
\text { municipios estudiados con } \\
\text { pueblos limítrofes. }\end{array}$ \\
\hline
\end{tabular}




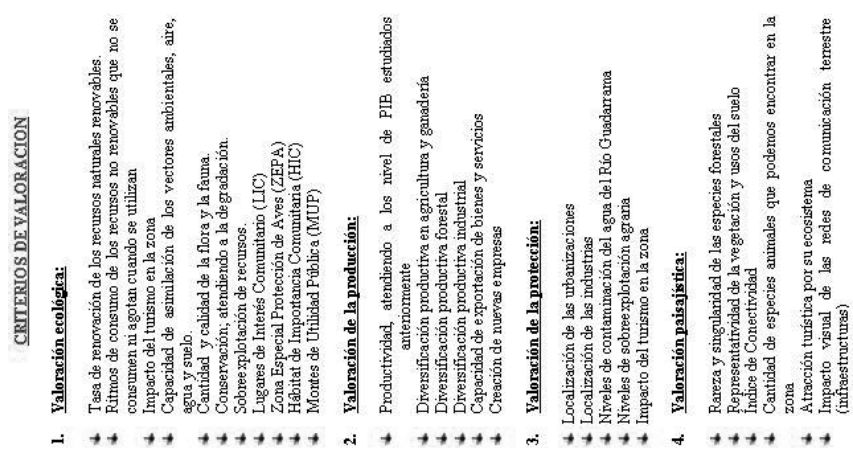

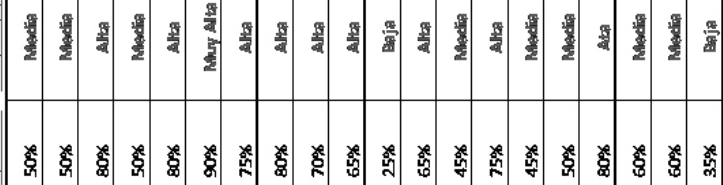

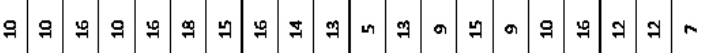

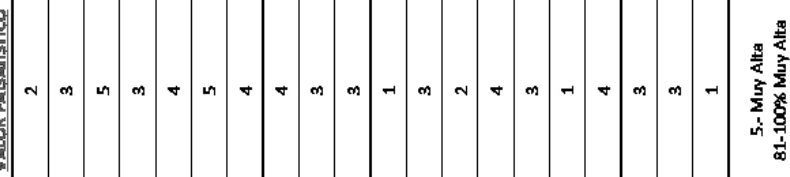

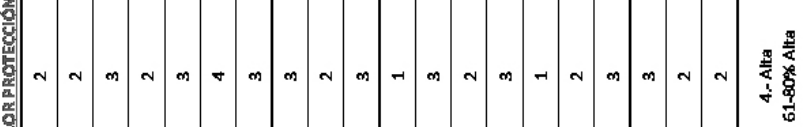

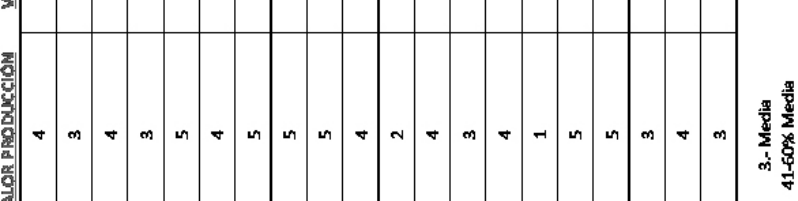

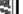

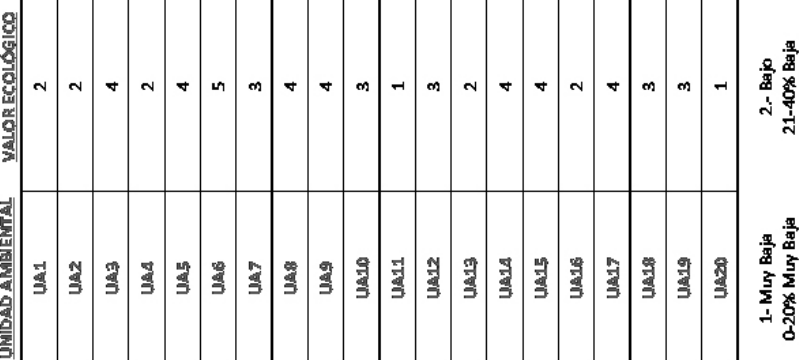




\section{ANÁLISIS DE IMPACTO/APTITUD DE ACTIVIDADES EN LAS UNIDA- DES AMBIENTALES}

\subsection{MATRIZ DE IMPACTO}

Las cualidades del territorio pueden haber sufrido cambios producto del desarrollo de las actividades a través de la historia de uso que ha tenido el mismo. Esto se puede ver reflejado en modificaciones que este territorio manifiesta en forma de impactos, los cuales deben ser tenidos en cuenta y convenientemente catalogados en cuanto a su signo, magnitud e intensidad para integrar el análisis y establecer un correcto diagnóstico sectorial. Los impactos son así identificados y valorados para obtener elementos que permitan regular o restringir los usos pudiéndose obtener mapas de zonas con necesidades de protección, recuperación o aún susceptibles a ser deterioradas (vulnerabilidad).

- Impacto:

- Efecto o alteración que una actuación determinada produce sobre el medio. Es inherente a la actividad, pero su magnitud dependerá del medio receptor (de su calidad y de su fragilidad)

- Tipos de impactos

- Fragilidad / vulnerabilidad:

- Grado de susceptibilidad al deterioro / mayor o menor facilidad de que el medio o alguno de los componentes se degrade ante las influencias humanas (inverso a la "capacidad de absorción")

- Es inherente al territorio, a sus componentes

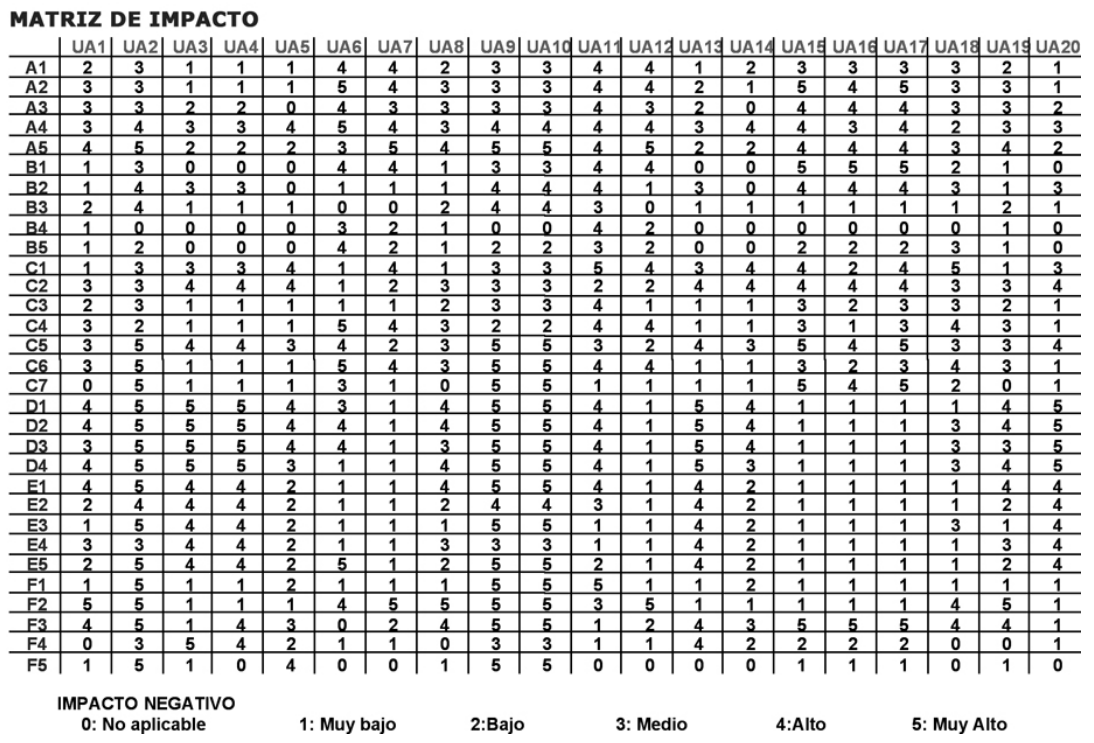

Fuente: Elaboración propia 


\subsection{MATRIZ DE APTITUD}

El territorio con sus recursos naturales y características, debe consecuentemente ser valorado en los aspectos de la capacidad intrínseca para alojar dichas actividades y especificar qué grado de soporte tiene para las mismas. Por lo tanto, es necesario contar con los conocimientos del área; asignar valores a los recursos presentes en el medio para soportar las actividades y definir sus posibilidades de realización.

- Aptitud:

- Medida en que un punto del espacio, los recursos que en él coexisten pueden satisfacer los requerimientos de una determinada actividad.

- Incluye los riesgos para una actividad

- Gradación o rango de aptitudes para una actividad en un territorio dado

- Calidad:

- Grado de excelencia ("mérito") del medio o de alguno de sus componentes para no ser alterado o destruido

- Puede estar referida a estas cualidades: diversidad, rareza, singularidad, escasez - Los valores en los que se basa pueden ser: naturales, relativos a la productividad (agraria o ecológica) o culturales (paisaje, huellas históricas...)

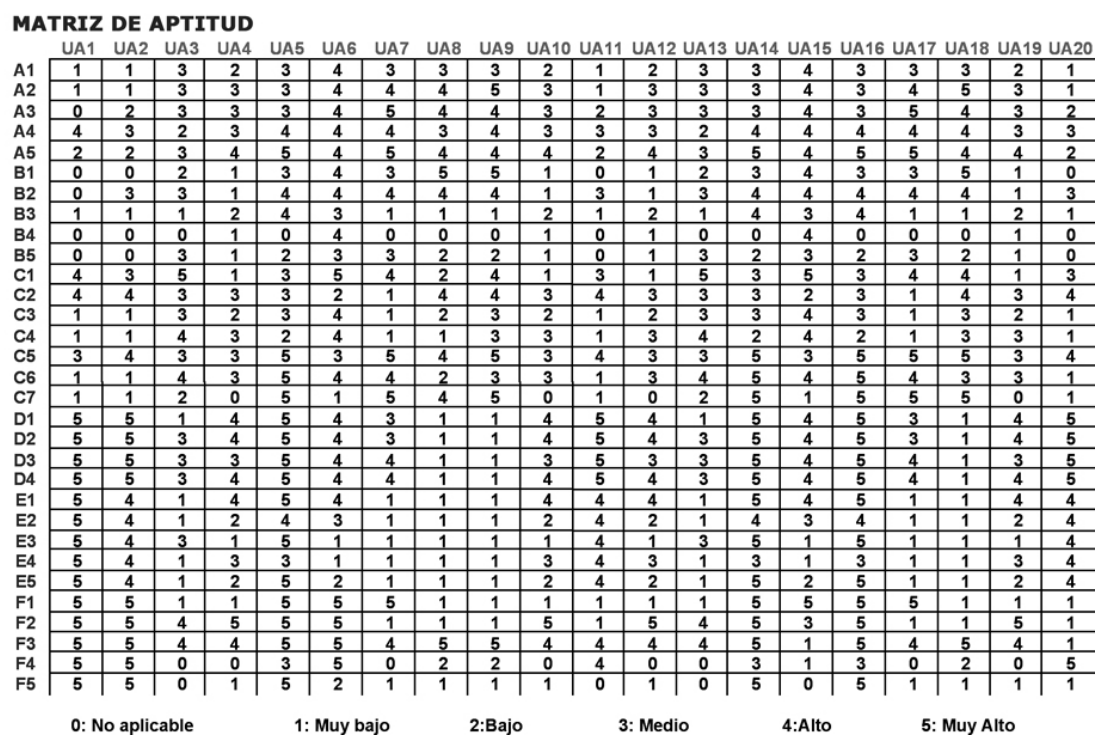

Fuente: Elaboración propia

\subsection{CAPACIDAD DE ACOGIDA}

- Grado de idoneidad o cabida del territorio para las distintas actividades a ordenar 
- Expresión de las relaciones entre las características físicas, biológicas y perceptibles del medio y las actividades humanas actuales o potenciales en él

- Puede establecerse de tres formas:

- Restrictiva (fundamentada en la predicción de impactos)

- Positiva (fundamentada en estudios de aptitud)

- Integral (conjunción de ambas); se estima a partir de la aplicación de la matriz impacto / aptitud sobre cada unidad ambiental.

- Gradación de niveles de capacidad de acogida

- Actividades vocacionales

- Actividades compatibles sin limitaciones

- Actividades compatibles con limitaciones

- Actividades incompatibles

- Los umbrales máximos de impacto y mínimos de aptitud marcan las categorías a partir de las cuales la implantación de la actividad debe ser inviable

- Actividad en origen de tipo cualitativo, basada en opinión de expertos, equipos interdisciplinares

MATRIZ CAPACIDAD DE CARGA

\begin{tabular}{|c|c|c|c|c|c|c|c|c|c|c|c|c|c|c|c|c|c|c|c|c|}
\hline & UA1 & UA2 & UA3 & UA4 & UA5 & UAG & UA7 & JA & UAS & & & $U A$ & & $\Delta 1$ & & & $U A$ & UA & UA1 & UA20 \\
\hline A1 & 1 & 2 & -2 & -1 & -2 & 0 & 1 & -1 & 0 & 1 & 3 & 2 & -2 & -1 & -1 & 0 & 0 & 0 & 0 & 0 \\
\hline A2 & 2 & 2 & -2 & -2 & -2 & 1 & 0 & -1 & -2 & 0 & 3 & 1 & -1 & -2 & 1 & 1 & 1 & -2 & 0 & 0 \\
\hline A3 & 3 & 1 & -1 & -1 & -3 & 0 & -2 & -1 & -1 & 0 & 2 & 0 & -1 & -3 & 0 & 1 & -1 & -1 & 0 & 0 \\
\hline A4 & -1 & 1 & 1 & 0 & 0 & 1 & 0 & 0 & 0 & 1 & 1 & 1 & 1 & 0 & 0 & -1 & 0 & -2 & 0 & 0 \\
\hline A5 & 2 & 3 & -1 & -2 & -3 & -1 & 0 & 0 & 1 & 1 & 2 & 1 & -1 & -3 & 0 & -1 & -1 & -1 & 0 & 0 \\
\hline B1 & 1 & 3 & -2 & -1 & -3 & 0 & 1 & -4 & -2 & 2 & 4 & 3 & -2 & -3 & 1 & 2 & 2 & -3 & 0 & 0 \\
\hline B2 & 1 & 1 & 0 & 2 & -4 & -3 & -3 & -3 & 0 & 3 & 1 & 0 & 0 & -4 & 0 & 0 & 0 & -1 & 0 & 0 \\
\hline B3 & 1 & 3 & 0 & -1 & -3 & -3 & -1 & 1 & 3 & 2 & 2 & -2 & 0 & -3 & -2 & -3 & 0 & 0 & 0 & 0 \\
\hline $\mathrm{B} 4$ & 1 & 0 & 0 & -1 & 0 & -1 & 2 & 1 & 0 & -1 & 4 & 1 & 0 & 0 & -4 & 0 & 0 & 0 & 0 & 0 \\
\hline B5 & 1 & 2 & -3 & -1 & -2 & 1 & -1 & -1 & 0 & 1 & 3 & 1 & -3 & -2 & -1 & 0 & -1 & 1 & 0 & 0 \\
\hline C1 & -3 & 0 & -2 & 2 & 1 & -4 & 0 & -1 & -1 & 2 & 2 & 3 & -2 & 1 & -1 & -1 & 0 & 1 & 0 & 0 \\
\hline $\mathrm{C} 2$ & -1 & -1 & 1 & 1 & 1 & -1 & 1 & -1 & -1 & 0 & -2 & -1 & 1 & 1 & 2 & 1 & 3 & -1 & 0 & 0 \\
\hline C3 & 1 & 2 & -2 & -1 & -2 & -3 & 0 & 0 & 0 & 1 & 3 & -1 & -2 & -2 & -1 & -1 & 2 & 0 & 0 & 0 \\
\hline $\mathrm{C4}$ & 2 & 1 & -3 & -2 & -1 & 1 & 3 & 2 & -1 & -1 & 3 & 1 & -3 & -1 & -1 & -1 & 2 & 1 & 0 & 0 \\
\hline C5 & 0 & 1 & 1 & 1 & -2 & 1 & -3 & -1 & 0 & 2 & -1 & -1 & 1 & -2 & 2 & -1 & 0 & -2 & 0 & 0 \\
\hline C6 & 2 & 4 & -3 & -2 & -4 & 1 & 0 & 1 & 2 & 2 & 3 & 1 & -3 & -4 & -1 & -3 & -1 & 1 & 0 & 0 \\
\hline C7 & -1 & 4 & -1 & 1 & -4 & 2 & -4 & -4 & 0 & 5 & 0 & 1 & -1 & -4 & 4 & -1 & 0 & -3 & 0 & 0 \\
\hline D1 & -1 & 0 & 4 & 1 & -1 & -1 & -2 & 3 & 4 & 1 & -1 & -3 & 4 & -1 & -3 & -4 & -2 & 0 & 0 & 0 \\
\hline D2 & -1 & 0 & 2 & 1 & -1 & 0 & -2 & 3 & 4 & 1 & -1 & -3 & 2 & -1 & -3 & -4 & -2 & 2 & 0 & 0 \\
\hline D3 & -2 & 0 & 2 & 2 & -1 & 0 & -3 & 2 & 4 & 2 & -1 & -2 & 2 & -1 & -3 & -4 & -3 & 2 & 0 & 0 \\
\hline D4 & -1 & 0 & 2 & 1 & -2 & -3 & -3 & 3 & 4 & 1 & -1 & -3 & 2 & -2 & -3 & -4 & -3 & 2 & 0 & 0 \\
\hline E1 & -1 & 1 & 3 & 0 & -3 & -3 & 0 & 3 & 4 & 1 & 0 & -3 & 3 & -3 & -3 & -4 & 0 & 0 & 0 & 0 \\
\hline E2 & -3 & 0 & 3 & 2 & -2 & -2 & 0 & 1 & 3 & 2 & -1 & -1 & 3 & -2 & -2 & -3 & 0 & 0 & 0 & 0 \\
\hline E3 & -4 & 1 & 1 & 3 & -3 & 0 & 0 & 0 & 4 & 4 & -3 & 0 & 1 & -3 & 0 & -4 & 0 & 2 & 0 & 0 \\
\hline E4 & -2 & -1 & 3 & 1 & -1 & 0 & 0 & 2 & 2 & 0 & -3 & -2 & 3 & -1 & 0 & -2 & 0 & 0 & 0 & 0 \\
\hline E5 & -3 & 1 & 3 & 2 & -3 & 3 & 0 & 1 & 4 & 3 & -2 & -1 & 3 & -3 & -1 & -4 & 0 & 0 & 0 & 0 \\
\hline F1 & -4 & 0 & 0 & 0 & -3 & -4 & -4 & 0 & 4 & 4 & 4 & 0 & 0 & -3 & -4 & -4 & -4 & 0 & 0 & 0 \\
\hline $\mathrm{F2}$ & 0 & 0 & -3 & -4 & -4 & -1 & 4 & 4 & 4 & 0 & 2 & 0 & -3 & -4 & -2 & -4 & 0 & 3 & 0 & 0 \\
\hline F3 & -1 & 0 & -3 & 0 & -2 & -5 & -2 & -1 & 0 & 1 & -3 & -2 & 0 & -2 & 4 & 0 & 1 & -1 & 0 & 0 \\
\hline $\mathrm{F} 4$ & -5 & -2 & 5 & 4 & -1 & -4 & 1 & -2 & 1 & 3 & -3 & 1 & 4 & -1 & 1 & -1 & 2 & -2 & 0 & -4 \\
\hline F5 & -4 & 0 & 1 & -1 & -1 & -2 & -1 & 0 & 4 & 4 & 0 & -1 & 0 & -5 & 1 & -4 & 0 & -1 & 0 & -1 \\
\hline
\end{tabular}

Fuente: Elaboración propia 


\section{A. CLUSTER DE CONSERVACIÓN Y REGENERACIÓN DE LANATURALEZA}

Tal y como nos muestra el mapa de conservación y regeneración, encontramos lo siguiente;

- Las zonas con mayor capacidad de carga las encontramos en las Dehesas con Pinares negros puesto que la producción y reforestación de la misma se está realizando de manera sostenible, sin llevar a cabo talas o quemas indiscriminadas, no se produce sobreexplotación de los recursos naturales y la limpieza del medio es realizada tanto por los agricultores como por los animales. Igualmente, las zonas de dehesa y agricultura leñosa con usos de explotación forestal y ganadero, donde no existe urbanismo ni turismo descontrolado.

- Las zonas con capacidad de carga media se localizan, tal y como se nos muestra en el mapa, la mayor parte del Parque Regional, el entorno de Sevilla la Nueva y los campos agrarios de Navalcarnero y Villamanta, junto con el entorno del propio Arroyo Grande.

- Las de menor capacidad de carga son los núcleos urbanos principales de cada ámbito municipal, o los polígonos industriales cuyas capacidades de carga de conservación y regeneración son muy bajas, a excepción de Villamanta que es baja. De igual modo, poseen baja capacidad de carga los centros de intercepción con estos centros, tales como la zona de interfluvio, el centro residencial y de uso forestal del Parque Regional y la mayor parte del término municipal de El Álamo.

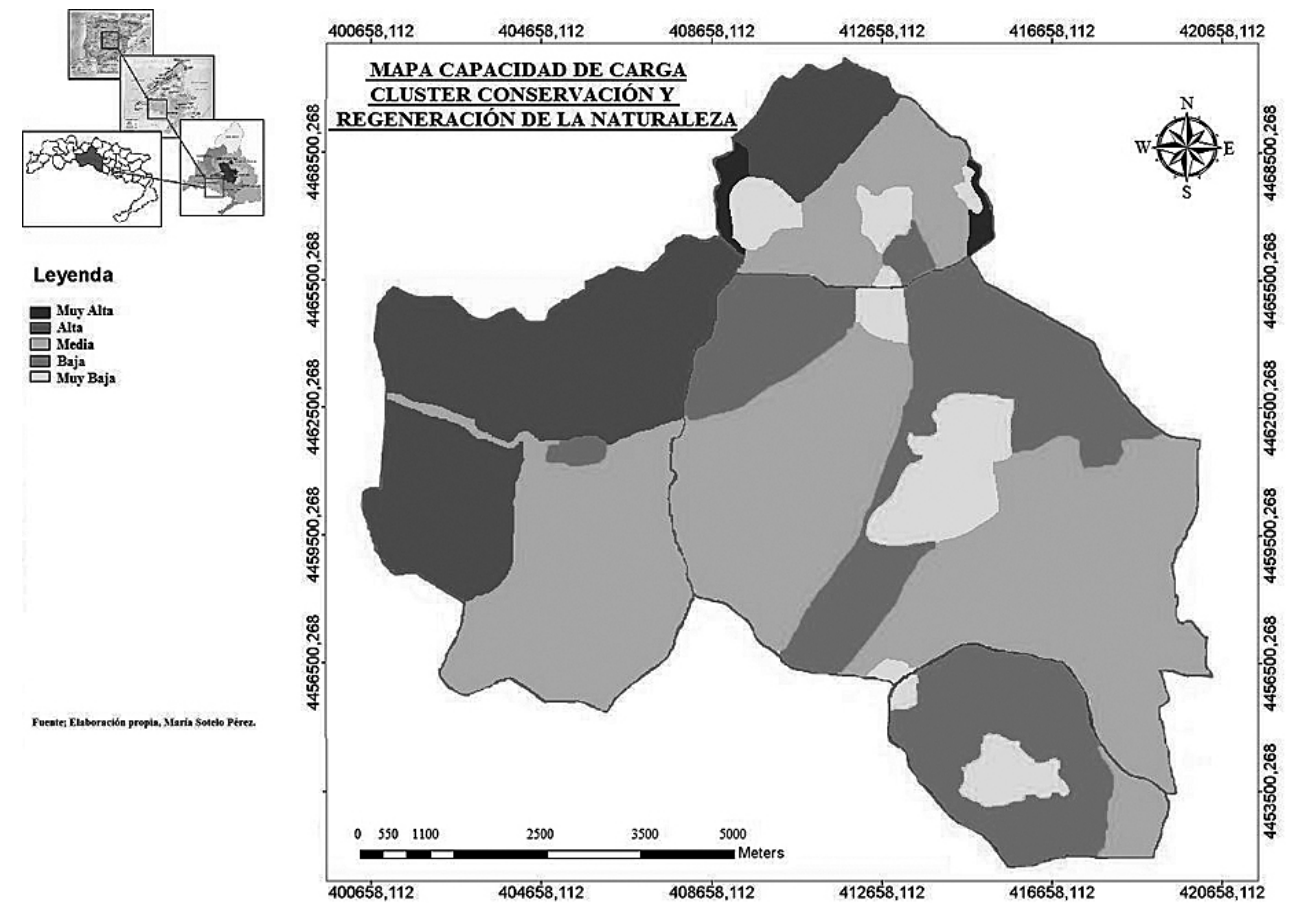

Fuente: Elaboración propia 


\section{B. CLUSTER DE ESPARCIMIENTO Y DEPORTES AL AIRE LIBRE.}

- Atendiendo al cluster de esparcimiento y deportes al aire libre, podemos observar que es prácticamente análogos puesto que las zonas de mayor conservación y regeneración son las más atractivas para el desarrollo de actividades de ocio, esparcimiento y deportes al aire libre, sobre todo vinculando estos últimos con la naturaleza, el medio natural tales como el excursionismo, a pesca o los deportes acuáticos vs. rurales. De igual modo cabe destacar una cuestión relativamente interesante y es que algunos núcleos urbanos como Villamanta o El Álamo tienen una capacidad de carga relativamente interesante para el desarrollo de estas actividades, con lo que se puede potenciar bastante como motor dinamizador de dicho ámbito de planificación.

- Con ello podemos afirmar que es una zona de gran potencial en términos deportivos, lúdicos y de esparcimiento, con lo que incidirá positivamente en el uso de sus potencialidades a la hora de planificar, sobre todo vinculadas con el mundo rural.

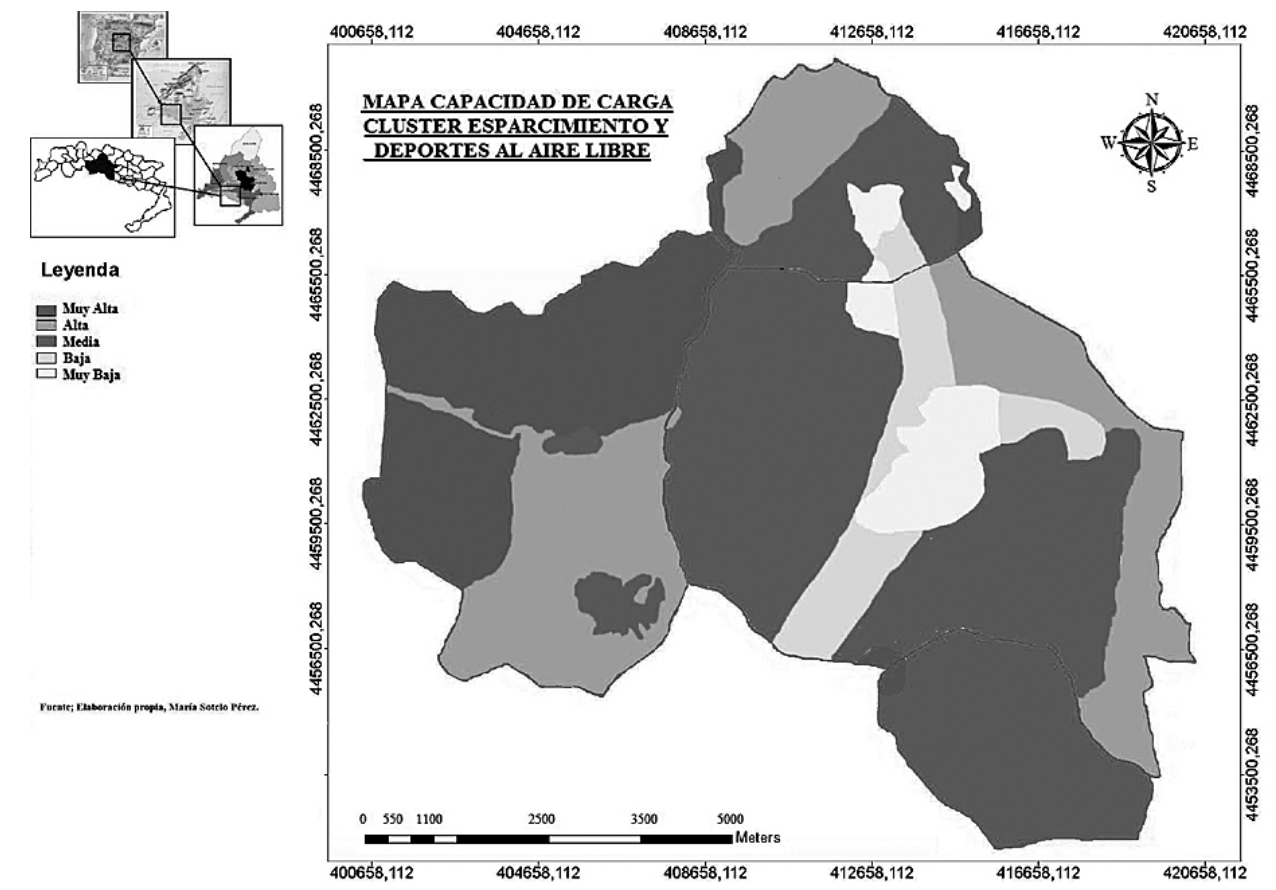

Fuente: Elaboración propia

\section{CLUSTER DE URBANIZACIÓN E INFRAESTRUCTURAS.}

Cabe destacar que, en este caso, el mapa refleja todo lo contrario a lo expuesto anteriormente, ya que las zonas con mayor capacidad de carga en las zonas urbanas, en los núcleos residenciales, y menor capacidad de carga en las áreas protegidas, naturales, conservados y lugares de esparcimiento. Con todo ello afirmar que; 
- Las zonas con mayor capacidad de carga las encontramos en las zonas urbanas, en los núcleos urbanos principales y secundarios de cada uno de los municipios, urbanizaciones, y zonas de alta capacidad de carga en la zona del interfluvio.

- En cuanto a las zonas con capacidad de carga media encontramos zonas limítrofes al Parque Regional, incluso en una zona de urbanizaciones actuales dentro de los propios límites del Parque.

- Las zonas con menor capacidad de carga, tal y como ya he descrito anteriormente, la podemos localizar en el propio Parque Regional, prácticamente la totalidad del término municipal de Villamanta, el oeste del término municipal de Navalcarnero y de Sevilla la Nueva.

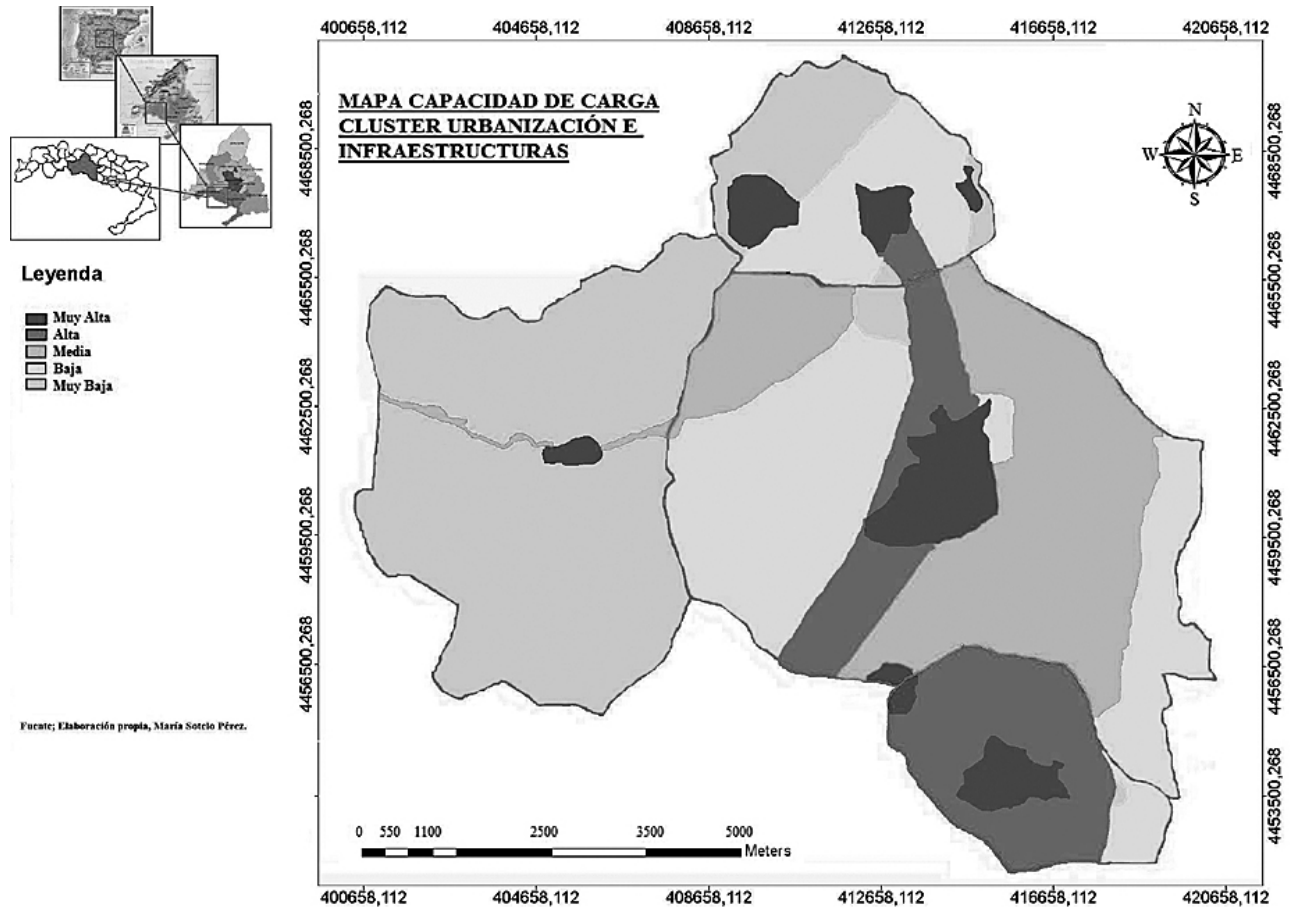

Fuente: Elaboración propia

\section{CLUSTER DE ACTIVIDADES AGRARIAS}

Tal y como nos muestra el mapa de actividades agrarias, encontramos lo siguiente;

- Las zonas con mayor capacidad de carga las encontramos en las Dehesas con Pinares negros puesto que la producción y reforestación de la misma se está realizando de manera sostenible, sin llevar a cabo talas o quemas indiscriminadas, no se produce sobreexplotación de los recursos naturales y la limpieza del medio es realizada tanto por los agricultores como por los animales. Igualmente, las zonas de dehesa y agricultura leñosa con usos de 
explotación forestal y ganadero, donde no existe urbanismo ni turismo descontrolado.

- Las zonas con capacidad de carga media se localizan, tal y como se nos muestra en el mapa, la mayor parte del Parque Regional, el entorno de Sevilla la Nueva y los campos agrarios de Navalcarnero y Villamanta, junto con el entorno del propio Arroyo Grande.

- Las de menor capacidad de carga son los núcleos urbanos principales de cada ámbito municipal, o los polígonos industriales cuyas capacidades de carga de conservación y regeneración son muy bajas, a excepción de Villamanta que es baja. De igual modo, poseen baja capacidad de carga los centros de intercepción con estos centros, tales como la zona de interfluvio, el centro residencial y de uso forestal del Parque Regional y la mayor parte del término municipal de El Álamo.

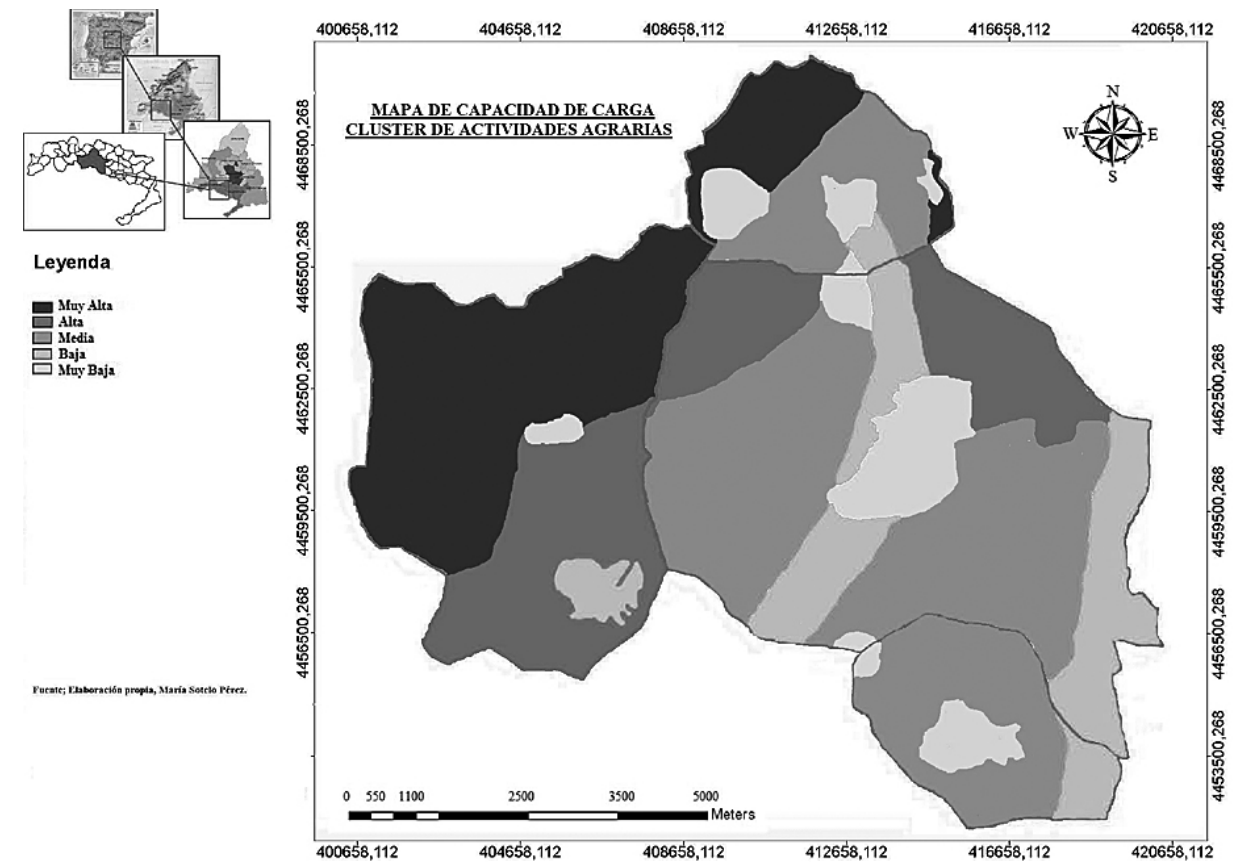

Fuente: Elaboración propia

Atendiendo a todos los datos y resultados obtenidos anteriormente, podemos realizar una aproximación de cuales son los problemas claves o, por lo menos, relevantes en nuestro ámbito de planificación. 


\section{DIAGNÓSTICO PARCIAL DE LA PROBLEMÁTICA DEL MEDIO FÍSICO}

- Falta de conservación, que conlleva la degradación ambiental del Parque Regional del Guadarrama. Falta de información y educación ambiental.

- Falta de consenso entre entidades locales y la Administración de la Comunidad Autónoma de Madrid.

- Cierto aislamiento con respecto a los núcleos urbanos de Madrid capital y Toledo

- Contaminación del Río Guadarrama por la falta de una buena recogida, y de residuos.

- Problema de abastecimiento de agua potable.

- Construcción de urbanizaciones e industrias en espacios naturales protegidos.

- Las zonas o hábitats de interés paisajístico esta sobreexplotado

- Existencia de un polígono industrial en el propio Parque, amén de creación de urbanizaciones dentro del mismo.

- El Parque es atravesado por múltiples vías de comunicación terrestres.

- Se fomenta el uso del transporte privado.

\section{DIAGNÓSTICO PARCIAL DE LA PROBLEMÁTICA DEL SISTEMA DE ASENTAMIENTOS}

- Aislamiento de algunos núcleos urbanos, sobre todo de las nuevas urbanizaciones.

- Falta de comunicación, sobre todo en transporte público, con la corona metropolitana de Madrid.

- Falta de conservación del Patrimonio Cultural, sobre todo iglesias de Villamanta y Sevilla la Nueva.

- Falta de una comunicación estructurante del medio, entre los núcleos principales (sobre todo, falta de información de las direcciones).

- Falta de orden lógico en la planificación urbana; caos urbanístico, sobre todo en Navalcarnero.

- Problemas de sostenibilidad; económica, ecológica y social.

\section{DIAGNÓSTICO INTEGRADO}

En el siguiente apartado se sintetiza el diagnóstico de la situación actual del ámbito de estudio a partir del análisis realizado, de la inclusión de los resultados obtenidos a través de las matrices de impacto, aptitud y capacidad de carga; y, teniendo en cuenta la experiencia acumulada en el estudio previo realizado. Dicho diagnóstico se desarrolla a través de matrices DAFO que muestran los puntos fuertes, disparidades y lagunas para los diferentes sectores estudiados. Las matrices DAFO cons- 
tituyen una herramienta para ordenar y evaluar la naturaleza de los factores que actúan como condicionantes sobre un determinado territorio o sector económico. Dichos factores se clasifican como Debilidades, Amenazas, Fortalezas y Oportunidades de acuerdo a la siguiente metodología:

- Origen del factor: el factor puede ser endógeno o exógeno.

- Efectos que puede ocasionar: positivos o negativos.

El cruce de las anteriores características de cada factor (origen y efectos) permite clasificar a éstos en cada una de las cuatro componentes de la matriz DAFO, y posteriormente analizar las estrategias que permitan sacar provecho a las capacidades de la zona;

\begin{tabular}{|c|c|c|c|c|c|c|}
\hline $\begin{array}{c}\text { Deficiente valora- } \\
\text { ción del medio } \\
\text { natural }\end{array}$ & $\begin{array}{c}\text { Escasa valora- } \\
\text { ción del patrimo- } \\
\text { nio cultural }\end{array}$ & $\begin{array}{l}\text { Deficiencias en } \\
\text { el sistema pro- } \\
\text { ductivo local }\end{array}$ & $\begin{array}{l}\text { Deficiente for- } \\
\text { mación de recur- } \\
\text { sos humanos }\end{array}$ & $\begin{array}{l}\text { Deficiencias en } \\
\text { infraestructuras y } \\
\text { equipamientos }\end{array}$ & $\begin{array}{l}\text { Deficiencias en la } \\
\text { gestión institucio- } \\
\text { nal del desarrollo }\end{array}$ & $\begin{array}{c}\text { Escasa participa- } \\
\text { ción social en la } \\
\text { conservación del } \\
\text { Parque }\end{array}$ \\
\hline $\begin{array}{c}\text { Inadecuado apro- } \\
\text { vechamiento de los } \\
\text { recursos naturales }\end{array}$ & $\begin{array}{c}\text { Escaso conoci- } \\
\text { miento y difusión } \\
\text { del patrimonio } \\
\text { cultural }\end{array}$ & $\begin{array}{c}\text { Escasa transfor- } \\
\text { mación local de } \\
\text { los recursos }\end{array}$ & $\begin{array}{c}\text { Deficiencias en } \\
\text { el mercado de } \\
\text { trabajo local }\end{array}$ & $\begin{array}{c}\text { Déficit de infraestruc- } \\
\text { turas públicas; abaste- } \\
\text { cimiento de agua }\end{array}$ & $\begin{array}{c}\text { Deficiencias en } \\
\text { el ordenamiento } \\
\text { urbano de algu- } \\
\text { nos núcleos } \\
\text { municipales }\end{array}$ & $\begin{array}{c}\text { Escasa cultura } \\
\text { emprendedora } \\
\text { local }\end{array}$ \\
\hline $\begin{array}{l}\text { Degradación del } \\
\text { medio natural }\end{array}$ & $\begin{array}{c}\text { No se saca todo } \\
\text { el partido posible } \\
\text { al patrimonio } \\
\text { cultural como } \\
\text { centro de atrac- } \\
\text { ción turística }\end{array}$ & $\begin{array}{c}\text { Baja diversifica- } \\
\text { ción productiva } \\
\text { local, sobre todo } \\
\text { industrial }\end{array}$ & $\begin{array}{c}\text { Problemas en la } \\
\text { formación de } \\
\text { los recursos } \\
\text { humanos, como } \\
\text { consecuencia de } \\
\text { la inmigración }\end{array}$ & $\begin{array}{l}\text { Deficiencias en las } \\
\text { infraestructuras via- } \\
\text { rias; de ámbito local }\end{array}$ & $\begin{array}{c}\text { Reducida coordina- } \\
\text { ción institucional }\end{array}$ & $\begin{array}{c}\text { Escasa articula- } \\
\text { ción social y baja } \\
\text { participación }\end{array}$ \\
\hline $\begin{array}{l}\text { Deficiente ges- } \\
\text { tión del medio } \\
\text { natural }\end{array}$ & $\begin{array}{c}\text { Deficiencias en la } \\
\text { gestión del patri- } \\
\text { monio cultural }\end{array}$ & $\begin{array}{l}\text { Deficiente ges- } \\
\text { tión empresarial }\end{array}$ & $\begin{array}{c}\text { Falta de investi- } \\
\text { gación para el } \\
\text { desarrollo local } \\
\text { sostenible }\end{array}$ & $\begin{array}{c}\text { Deficiencias en las } \\
\text { infraestructuras } \\
\text { ambientales }\end{array}$ & $\begin{array}{c}\text { Deficiencias en la } \\
\text { planificación para } \\
\text { el desarrollo }\end{array}$ & $\begin{array}{c}\text { Baja cooperación } \\
\text { público-privado }\end{array}$ \\
\hline $\begin{array}{l}\text { Deficiencias en el } \\
\text { ciclo del agua }\end{array}$ & & $\begin{array}{c}\text { Deficiente oferta } \\
\text { de servicios de } \\
\text { apoyo a la pro- } \\
\text { ducción }\end{array}$ & $\begin{array}{l}\text { Escasa investi- } \\
\text { gación y des- } \\
\text { arrollo en } \mathrm{I}+\mathrm{D}+\mathrm{i} \\
\text { local }\end{array}$ & $\begin{array}{c}\text { Déficit de equipa- } \\
\text { mientos y servicios } \\
\text { sociales }\end{array}$ & & $\begin{array}{c}\text { Falta de comuni- } \\
\text { cación entre enti- } \\
\text { dad local y regio- } \\
\text { nal }\end{array}$ \\
\hline $\begin{array}{c}\text { Escasa educación } \\
\text { ambiental; paten- } \\
\text { te en la conserva- } \\
\text { ción del Parque } \\
\text { (sobre todo del } \\
\text { río Guadarrama) }\end{array}$ & & $\begin{array}{c}\text { Excesiva depen- } \\
\text { dencia del centro } \\
\text { comunitario de } \\
\text { Madrid }\end{array}$ & & & & \\
\hline
\end{tabular}




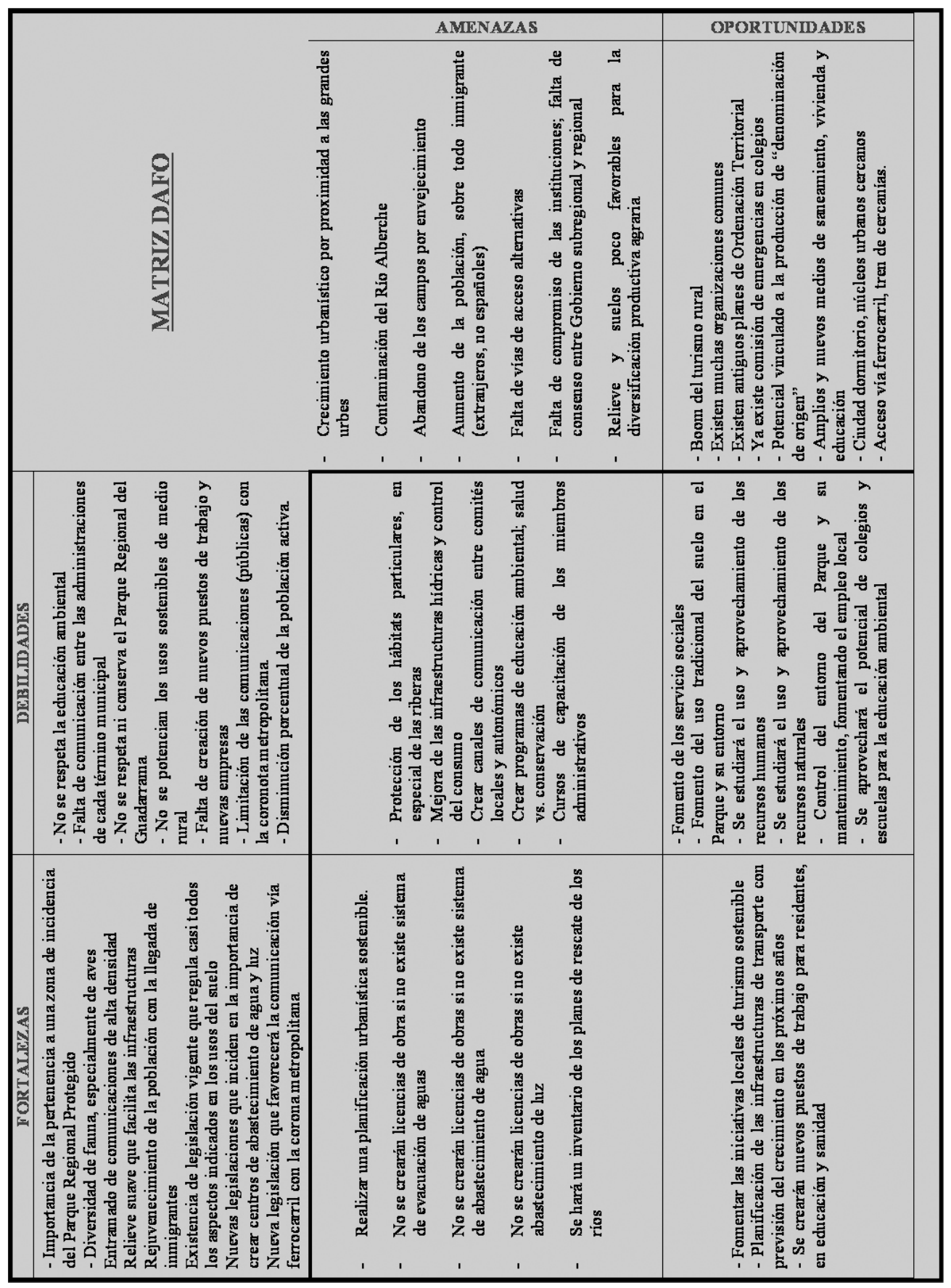


- Debilidades: Factores endógenos negativos.

- Amenazas: Factores exógenos negativos.

\section{DEBILIDADES Y AMENAZAS}

- Envejecimiento de la población agrícola y falta de relevo generacional

- Escaso peso de las actividades agrarias en el empleo y poco valor añadido y escasa incorporación de tecnologías en la explotación

- Alto porcentaje de titulares de explotación con dedicación a la agricultura como actividad complementaria

- Progresivo abandono de cultivos tradicionales, y sobreexplotación con viñedos, olivares y encinares. Deterioro de ecosistemas agrarios

- Poca competitividad de las explotaciones por su escasa dimensión.

- Escasa diversificación de la economía agraria

- Bajas producciones y rendimientos en algunas zonas. Existencia de zonas que limitan el desarrollo de la agricultura, como son las zonas de cárcavas o el propio Parque Regional del Guadarrama.

- Escaso aprovechamiento de los recursos endógenos por parte del sector empresarial y escasa incorporación de buenas prácticas ambientales.

- Tasa de actividad femenina inferior a la media regional y tasa de paro femenina superior

- Necesidad de renovación de los establecimientos comerciales e incorporación de estándares de calidad.

- Baja rentabilidad de la artesanía como actividad económica

- Escasa formación especializada de la población activa

- Desaprovechamiento generalizado de los recursos endógenos de la comarca.

- Insuficiente patrocinio y promoción del patrimonio existente.

- Posible presión del turismo sobre los recursos naturales, en especial sobre el Parque Regional.

- La diseminación de núcleos poblacionales en algunos municipios dificulta el acceso a las redes de comunicación, tanto de infraestructuras como de telecomunicaciones.

- Transporte público insuficiente entre poblaciones y con la propia ciudad de Madrid

\section{FORTALEZAS Y OPORTUNIDADES}

- Producción agrícola de calidad (viñedos de denominación de origen) e incremento de la demanda de productos de calidad.

- Valoración de lo rural, aumentando la demanda de servicios de ocio. 
- Uso de nuevas tecnologías.

- Situación estratégica, por su cercanía a la corona metropolitana de Madrid y su proximidad a Toledo.

- Demanda de turismo rural de calidad, sobre todo vinculado al Parque Regional.

- Incremento de la demanda hostelera de turismo rural.

- Enriquecimiento cultural por el incremento de la inmigración.

- Gran dinamismo por tratarse de una ciudad dormitorio.

- Extensa red de caminos, vías pecuarias y carreteras, lo que favorece la comunicación tanto dentro como fuera del ámbito de planificación.

- Se encuadra dentro de la Red Natura 2000 con un Lugar de Interés Comunitario LIC y una Zona Especial Protección de Aves ZEPA

- Alta biodiversidad, sobre todo de flora.

- Gran potencial forestal y agrícola, sobre todo con producción de encinas, pinos negros, pinos silvestres y cultivos de regadío.

- La diseminación del urbanismo evita que se produzca una urbanización masiva y que esta sea absorbida rápidamente por Madrid, amén de por el corte transversal que ejerce de barrera natural, el Parque Regional

- Mejora de la calidad de vida de los habitantes, por el incremento del gasto público en inversiones sociales, tales como educación, sanidad y vivienda

\section{ESTRATEGIAS Y OBJETIVOS}

\section{ESTRATEGIAS}

- Evitar el deterioro del Parque Regional, eliminando de su entorno las urbanizaciones ilegales y los núcleos industriales.

- Mantener el orden territorial y, sobre todo, el orden urbanístico, mediante una correcta normativa urbanística.

- No crear nuevas licencias de obras si no existen sistemas de evacuación de residuos, abastecimiento de agua, abastecimiento de luz...

- Realizar un inventario de los planes de rescate de los ríos.

- Protección de los denominados "Mosaicos paisajísticos"

- Crear canales de comunicación entre comités locales y autonómicos.

- Crear programas de educación ambiental; salud vs. conservación

- Cursos de capacitación de los miembros administrativos.

- Crear nuevos puestos de trabajo para residentes en educación y sanidad

- Crear un centro de salud en Navalcarnero, para favorecer a los residentes de la zona

- Eliminar una de las ramificaciones de la autovía con dirección a Móstoles. 
- Favorecer un turismo sostenible, vinculado principalmente con el turismo rural y el turismo cultural

- Se estudiará el uso y aprovechamiento de los recursos naturales y humanos.

- Erradicar los vertidos ilegales y extremadamente contaminantes al río, mediante la creación de puntos limpios de recogida, reciclaje y depuración de residuos, tanto sólidos como líquidos.

- Dinamizar la economía del ámbito de planificación, sobre todo la vinculada con la artesanía tradicional, con el fin de atraer más población joven

- Evitar el aislamiento rural, fomentado el desarrollo del turismo y de una economía tradicional

\section{OBJETIVOS}

Mantener el orden territorial y, sobre todo, el orden urbanístico.

- Evitar la sobreexplotación territorial y e urbanismo descontrolado, masivo y caótico.

- Rescatar los ríos para favorecer el consumo de sus aguas.

- Mejorar la calidad de vida de los residentes con acceso a centros de salud, educación, abastecimiento de luz, agua, alcantarillado

- Evitar la contaminación de los ríos, mediante la creación de centros de depuración y reciclaje.

- Evitar el envejecimiento del lugar y el aislamiento rural.

- Favorecer el turismo rural

- Evitar el deterioro del Parque Regional por contaminación, mal uso-gestión y sobreexplotación

- Favorecer una agricultura de calidad, sacando el mayor partido posible a la agricultura vitivinícola de Denominación de Origen.

- Crear nuevos puestos de trabajo, y nuevas empresas que faciliten el dinamismo económico del lugar; vinculado al sector primario y terciario principalmente

- Favorecer un turismo sostenible, vinculado principalmente con el turismo rural y el turismo cultural

\section{PROUESTA DE MODELO TERRITORIAL: OBJETIVOS, PROPUESTAS Y CONCLUSIONES.}

OBJ 1: Un plan que genera ventajas competitivas en un contexto de cooperación entre urbano y territorio. Mantener el orden territorial y, sobre todo, el orden urbanístico. 

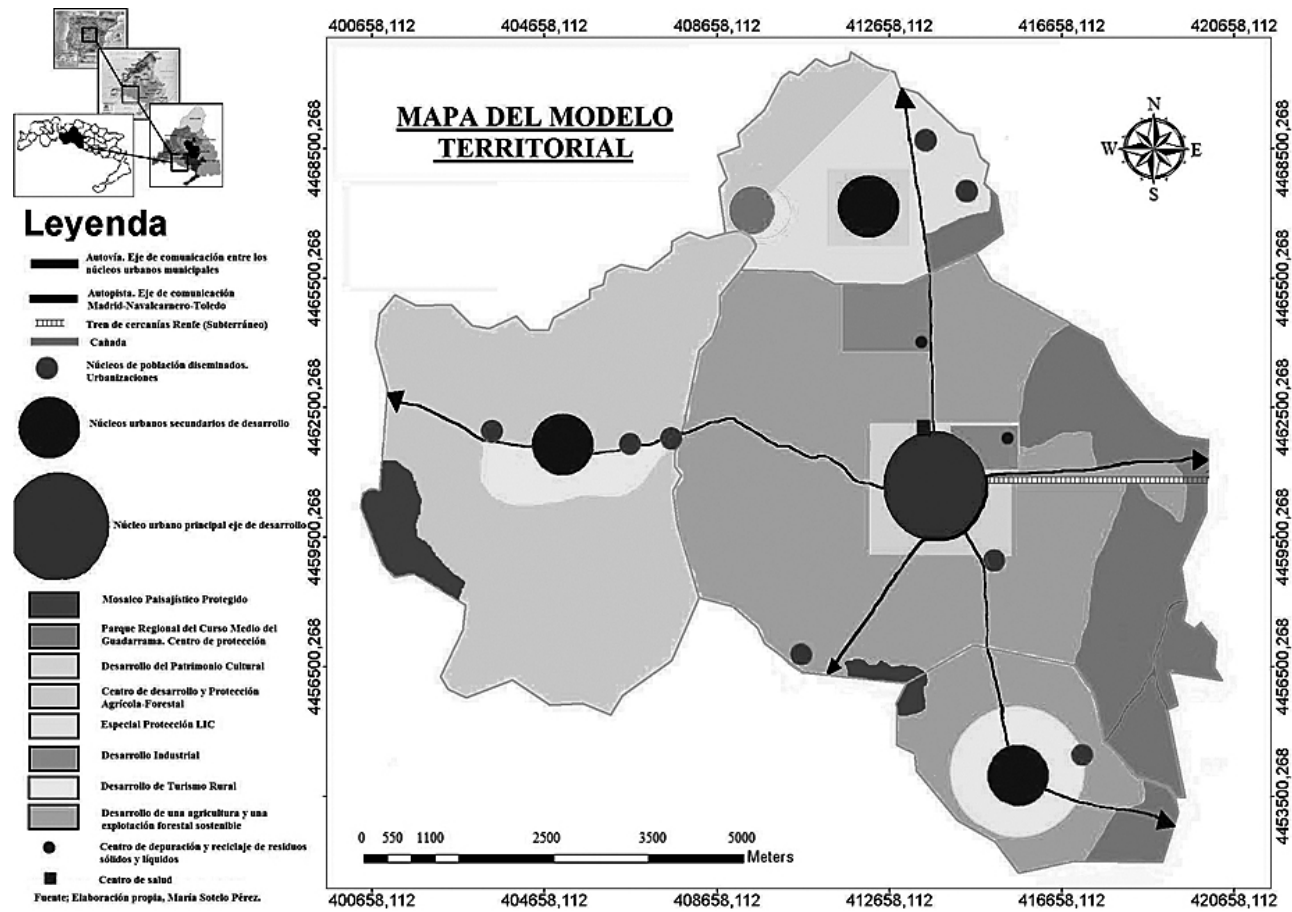

\section{JUSTIFICACIÓN:}

El reto más importante para la supervivencia de nuestros núcleos urbanos, en el futuro, será la capacidad para atraer y generar recursos humanos altamente preparados. En este sentido, las oportunidades profesionales, la infraestructura educativa, las opciones residenciales, la calidad de vida, el equilibrio social, la seguridad ciudadana, la oferta cultural y de ocio, y la calidad de los espacios urbanos van a ser factores clave de competitividad y conectividad. Los núcleos que tengan más éxitos en atraer y educar a los mejores talentos intelectuales y a los mejores trabajadores, son las que van a florecer. Las personas son el factor capital (capital humano) básico de la economía.

\section{PROPUESTA:}

Se debe definir los objetivos específicos del ámbito de planificación, capaces de dotar al municipio de los factores necesarios para generar ventaja competitiva en un contexto de cooperación entre los núcleos urbanos y el territorio. De igual modo, se deben configurar un conjunto de leyes y normas regionales que superen los límites subregionales, en materia de Ordenación Urbana y que favorezcan la comunicación y el desarrollo de una cooperación entre las Administraciones Locales y Autonómicas. Crear una vía de acceso a la comarca mediante la implantación de un tren de cercanías que comunique la comarca con Madrid. 
OBJ 2: Un plan comprometido con la cohesión y el desarrollo social. Crear nuevos puestos de trabajo, y nuevas empresas que faciliten el dinamismo económico del lugar; vinculado al sector primario y terciario principalmente

\section{JUSTIFICACIÓN:}

El espacio público puede ser uno de los principales puntos de referencia para la vida comunitaria en nuestra zona de estudio. La calida de los espacios públicos y su nivel de utilización es un claro exponente de la cohesión y el equilibrio social. Gran parte de los esfuerzos para conseguir un ámbito urbano integrado socialmente no pueden hacerlos solo las autoridades públicas. El dinamismo de la sociedad civil es esencial para lograr un ámbito urbano equilibrio e inclusiva. Los esfuerzos de una ciudad por lograr la inclusión de todos los ciudadanos tienen efectos evidentes en la capacidad competitiva del lugar y en su atractivo para el desarrollo de actividades económicas.

\section{PROPUESTA:}

Potencializar las iniciativas de creación de empresas vinculadas al turismo, la protección vs. cuidado del Parque Regional y la explotación vitivinícola, que dinamice a zona y favorezca el incremento de la mano de obra incidiendo en el mercado de trabajo.

OBJ 3: El paisaje: la singularidad de su patrimonio natural. Evitar el deterioro del Parque Regional por contaminación, mal uso-gestión y sobreexplotación

\section{JUSTIFICACIÓN:}

El riesgo para el mantenimiento del patrimonio natural aparece como una consecuencia directa, tanto de los procesos de degradación inducidos principalmente por las actuaciones sociales específicas ligadas a la expansión de la urbanización (de manera caótica), por la incidencia directa del turismo y de las malas praxis rurales o por transformaciones humanas que inciden negativamente sobre los ecosistemas naturales, favoreciendo la degradación y la pérdida de biodiversidad

\section{PROPUESTA:}

Crear una normativa (vinculante tanto en el ámbito local como autonómico) para evitar la entrada masiva y descontrolada al Parque, por lo que también es necesario crear puestos de trabajo de guardabosques que vigilen y controles las malas praxis que en el mismo se puedan realizar. De igual modo, será necesario eliminar tanto las urbanizaciones, los polígonos industriales y una de los ramales de la Autopista que se encuentran o atraviesan el propio Parque Regional. Por último, potenciar un uso sostenible del mismo mediante un turismo de calidad y un conjunto de medidas de conservación y protección tanto de la flora como de la fauna del Parque.

OBJ 4: Mejorar la calidad de vida de los residentes con acceso a centros de salud, educación, abastecimiento de luz, agua, alcantarillado 


\section{JUSTIFICACIÓN:}

Uno de los retos más importantes para la supervivencia de la comarca con identidad propia, en un futuro, será la capacidad para atraer y generar recursos humanos altamente preparados. En este sentido las oportunidades profesionales, las infraestructuras educativas, las operaciones residenciales, la calidad de vida, el equilibrio social, la seguridad ciudadana, la oferta cultural y de ocio, la calidad de los espacios urbanos va a ser un factor clave de competitividad.

\section{PROPUESTA:}

Por ello, amén de seguir fomentando el acceso de los residentes a una educación de calidad, es conveniente generalizarlo hacia una sanidad de fácil acceso y de calidad, por ello es conveniente crear un centro de salud dentro del propio ámbito de planificación, mejorar las condiciones de acceso al agua, creando mejores comunicaciones de la misma respecto al Canal de Isabel II, creación de depuradoras de agua y fomentar cursos de educación ambiental para los más jóvenes, enseñándoles no solo a respetar la naturaleza sino a hacer un uso sostenible de la misma con miras a su propio futuro.

OBJ 5. Comarca turística. Favorecer un turismo sostenible, vinculado principalmente con el turismo rural y el turismo cultural

\section{JUSTIFICACIÓN:}

La restauración, rehabilitación y revitalización del entorno y de los edificios que forman parte del Patrimonio histórico o urbanístico, es una parte inseparable del objetivo de desarrollo sostenible. Este, persigue el mantenimiento o incremento de los recursos y del capital natural, social, histórico y cultural que forma el bien más preciado de los pueblos. Si la conservación del patrimonio natura y del paisaje debe ser un objetivo básico en nuestro ámbito de planificación, dada la riqueza y el potencial d desarrollo que implican, algo similar ocurre con el patrimonio cultural, abocado a un incremento de los niveles de degradación como consecuencia de la amenaza que supone la especulación urbanística, de la falta de mantenimiento en algunos casos y por la degradación de ciertos espacios rurales.

\section{PROPUESTA:}

Constituir el núcleo urbano de Navalcarnero como núcleo de mayor especialización turística, sobre todo en el casco histórico del mismo. De igual modo, fomentando la aparición de pequeñas casas rurales en el entorno de los núcleos municipales de Sevilla a Nueva, Villamanta y el Álamo. Crear áreas turísticas de alojamiento: la diversificación de la oferta de alojamientos y los modelos de implantación de los operadores requieren la disponibilidad de pequeños establecimientos vs. viviendas rurales que se adecuen a un turismo rural y de calidad. 
Crear áreas de equipamientos turísticos: sobre todo vinculadas al esparcimiento y el ocio entorno al Parque Regional, un turismo de paseo, de disfrutar de la naturaleza y del campo.

OBJ 6: Evitar la contaminación de los ríos, mediante la creación de centros de depuración y reciclaje. Rescatar los ríos para favorecer el consumo de sus aguas.

\section{JUSTIFICACIÓN:}

Los ríos, al igual que los acuíferos suponen un importante aporte de agua a nuestro ámbito de planificación ya que las infraestructuras vinculadas a este recursos tan preciado son bastante limitadas, con lo que la mayor parte del agua que se emplea para regar las zonas de cultivo y para los usos agrarios proviene de todos los ríos y arroyos que encontramos en la zona de estudio. De igual modo, los residuos industriales y vertidos urbanos van a parar a este aporte de vida como son los río, contaminandolos.

\section{PROPUESTA:}

Favorecer el acceso al agua vía comunicación con el Canal de Isabel II, crear depuradoras y plantas de reciclaje de basuras y mejorar los servicios de recogidas de los mismo para evitar que los residuos vayan a parar a los arroyos.

OBJ 7: Evitar el envejecimiento del lugar y el aislamiento rural.

\section{JUSTIFICACIÓN:}

Es sorprendente que, en los albores del "milenio urbano", con una extraordinaria migración hacia las ciudades y pueblos en todos los países en desarrollo y con tasas de fecundidad bajas, la mayor parte de la población de personas de edad viva todavía en las zonas rurales. Pero esto tiene una explicación: muchos adultos jóvenes emigran a las zonas urbanas por razones económicas, dejando tras de sí a los ancianos; muchas personas de edad que han emigrado dejan de trabajar en las zonas urbanas y vuelven a las zonas rurales

\section{PROPUESTA:}

Atraer a población joven, favoreciendo la primera residencia en el ámbito de planificación. Todo ello se puede conseguir favoreciendo el acceso a la corona metropolitana de Madrid vía ferrocarril (tren RENFE), mejorando las condiciones laborales del lugar con la creación de nuevas empresas y, por ende, nuevos empleos; favoreciendo el incremento del gasto público en nuevas infraestructuras y equipamientos sociales, tanto educativos, sanitarios, de vivienda y lúdicos. 
OBJ 8: Favorecer una agricultura de calidad, sacando el mayor partido posible a la agricultura vitivinícola de Denominación de Origen.

\section{JUSTIFICACIÓN:}

Nos encontramos en una zona de fuerte crecimiento productivo vinculado al cultivo vitivinícola de gran calidad, "Denominación de origen", con lo que se nos plantea una situación de atractivo no sólo turístico sino que también de desarrollo rural vinculado a la agricultura.

\section{PROPUESTA:}

Crear reclamo propagandístico y de marketing para potenciar aún más la zona como centro de explotaciones vitivinícolas y favorecer a su vez, el incremento de las zonas agrícolas (aumentando las hectáreas) estrechamente relacionadas con la producción de vinos. También se pueden crear museos del vino y preparar visitas guiadas por la zona de cultivo y de producción del mismo.

\section{A MODO DE CONCLUSIONES}

Tras lo anteriormente expuesto podemos llegar a las conclusiones siguientes:

Nos encontramos, como primera conclusión, en un territorio en el que crecimiento demográfico es una consecuencia directa de la facilidad de acceso por vía carretera que ha facilitado el aumento de la población unida a la primera residencia (aunque también han aumentado las segunda residencia), y al incremento progresivo de la población inmigrante que accede a dicha zona por las actividades económicas vinculadas y con el hecho de que el precio del suelo y, por consiguiente, el precio de alquiler y de la compra de las viviendas es menor que en la corona metropolitana. Pese a todo, atendiendo a la superficie del territorio, no es esta una zona muy densamente poblada, en cuanto a primera residencia, pero, progresivamente va incrementándose el número de individuos residentes en la zona por lo que la densidad de población se incrementa, y sobre todo, se encuadra en os núcleos municipales de cada uno de los municipios que lo configuran.

En lo referente a la estructuración del territorio y al sistema tradicional de núcleos de población, segunda conclusión, nos encontramos ante cuatro núcleos base de población (población concentrada); correspondientes a los centros urbanos de cada uno de los municipios que configuran nuestra zona de estudio y, de forma aislada, algunos asentamientos dispersos en el territorio, correspondientes a urbanizaciones. Con todo, podemos delimitar un núcleo central o casco (casco antiguo), en torno a una plaza central (plaza mayor) sobre la cual comienza a extenderse de forma ordenada, bajo un plano irregular, el conjunto urbanístico de cada uno de los puntos centrales de edificación.

En el área de estudio, tercera conclusión, cobran especial importancia los espacios naturales protegidos; de forma concreta, nos encontramos el Parque Regional 
del Curso Medio del Río Guadarrama, espacio natural protegido de la Comunidad de Madrid, que se configura como una larga franja entorno al Río Guadarrama y sus afluentes. El Parque, como espacio natural protegido, posee un conjunto de singularidades geológicas, geomorfológicas, paisajísticas, hidrográficas, faunísticas y botánicas que han favorecido la inclusión de medidas de protección considerando el área de estudio como una Zona Especial de Protección de Aves (ZEPA), parajes pintorescos, mosaicos paisajísticos y Lugares de Interés Comunitario (LIC), entorno a la rivera del Río Guadarrama, encuadrando toda la zona de monte de nuestro área de estudio bajo la protección de la Ley Forestal de la Comunidad de Madrid. Este es un punto de referencia fundamental a la hora de tratar de la Ordenación del Territorio de este espacio.

En definitiva, nuestra zona de estudio presenta un fuerte crecimiento productivo vinculado al cultivo vitivinícola de gran calidad, "Denominación de origen", con lo que se nos plantea una situación de atractivo no sólo turístico sino que también de desarrollo rural vinculado a la agricultura.

\section{REFERENCIAS BIBLIOGRAFÍCAS}

DEMATTEIS, G Y GOVERNA, F. (2006): "Territorio y territorialidad en el desarrollo local. La contribución del modelo SloT". Boletín de la A.G E., no 41, pp. 31-58. ESPON (2007): "The territorial footprint of ageing.doc". www.ESPON.eu consulta septiembre 2007

GÓMEZ OREA, D. (2007). "Evaluación Ambiental Estratégica". Mundi Prensa. Madrid

LOZANO, P. (2003): "La ordenación territorial en el País Vasco. Debilidades, amenazas, fortalezas y oportunidades de la escala intermedia", en Investigaciones Geográficas, n. ${ }^{\circ}$ 32, Instituto Universitario de Geografía, Universidad de Alicante, pp. 157-176.

MATA OLMO, R.; GÓMEZ MENDOZA, J.; FERNÁNDEZ MUÑOZ, S. (2001): "Paisaje, calidad de vida y territorio", Análisis Local, 37: 27-40.

MATA. R. y SANZ, C. (dirs.); GÓMEZ, J.; LÓPEZ, N.; ALLENDE, F.; MOLINA, P.; GALIANA, L. (2003): “Atlas de los paisajes de España”, Madrid, Ministerio de Medio Ambiente. Secretaría General Técnica, $550 \mathrm{p}$.

SOTELO NAVALPOTRO, J.A. (1999): Modelos de Organización y desarrollo regional, Madrid, UCM/Oxford U.P, 165 págs.

SOTELO NAVALPOTRO, J.A. (1999): "Los Sistemas de Gestión Medioambiental: una aportación a la Ordenación del Territorio y del Medio Ambiente", Academia de las Ciencias, Homenaje a don Ángel Ramos, pp. 1485-1499.

SOTELO NAVALPOTRO, J.A. (2000): "El Medio Ambiente en España, hoy", Instituto de Estudios Económicos.

PLAN DE ORDENACIÓN URBANÍSTICA DE SANLUCAR LA MAYOR.

PLAN DE ORDENACIÓN URBANA DE LEVANTE ALMERIENSE.

PLAN DE ORDENACIÓN URBANA DE NAVALCARNERO.

PLAN DE ORDENACIÓN URBANA DE SEVILLA LA NUEVA. 
PLAN DE ORDENACIÓN URBANA DE EL ÁLAMO.

PLAN DE ORDENACIÓN URBANA DE VILLAMANTA.

INSTITUTO NACIONAL DE ESTADÍSTICA, INE (2011).

ESTADÍSTICAS “ALMUDENA” DE LA COMUNIDAD DE MADRID. 